partment

of Transportation

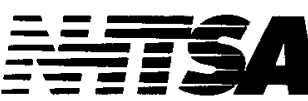

National Highway

Traffic Safety

Administration

Final Report

\title{
The Effectiveness of Laser and Radar Based Enforcement Programs for Deterrence of Speeding
}


This publication is distributed by the U.S. Department of Transportation, National Highway Traffic Safety Administration, in the interest of information exchange. The opinions, findings and conclusions expressed in this publication are those of the author(s) and not necessarily those of the Department of Transportation or the National Highway Traffic Safety Administration. The United States Government assumes no liability for its contents or use thereof. If trade or manufacturers' name or products are mentioned, it is because they are considered essential to the object of the publication and should not be construed as an endorsement. The United States Government does not endorse products or manufacturers. 
Technical Report Documentation Page

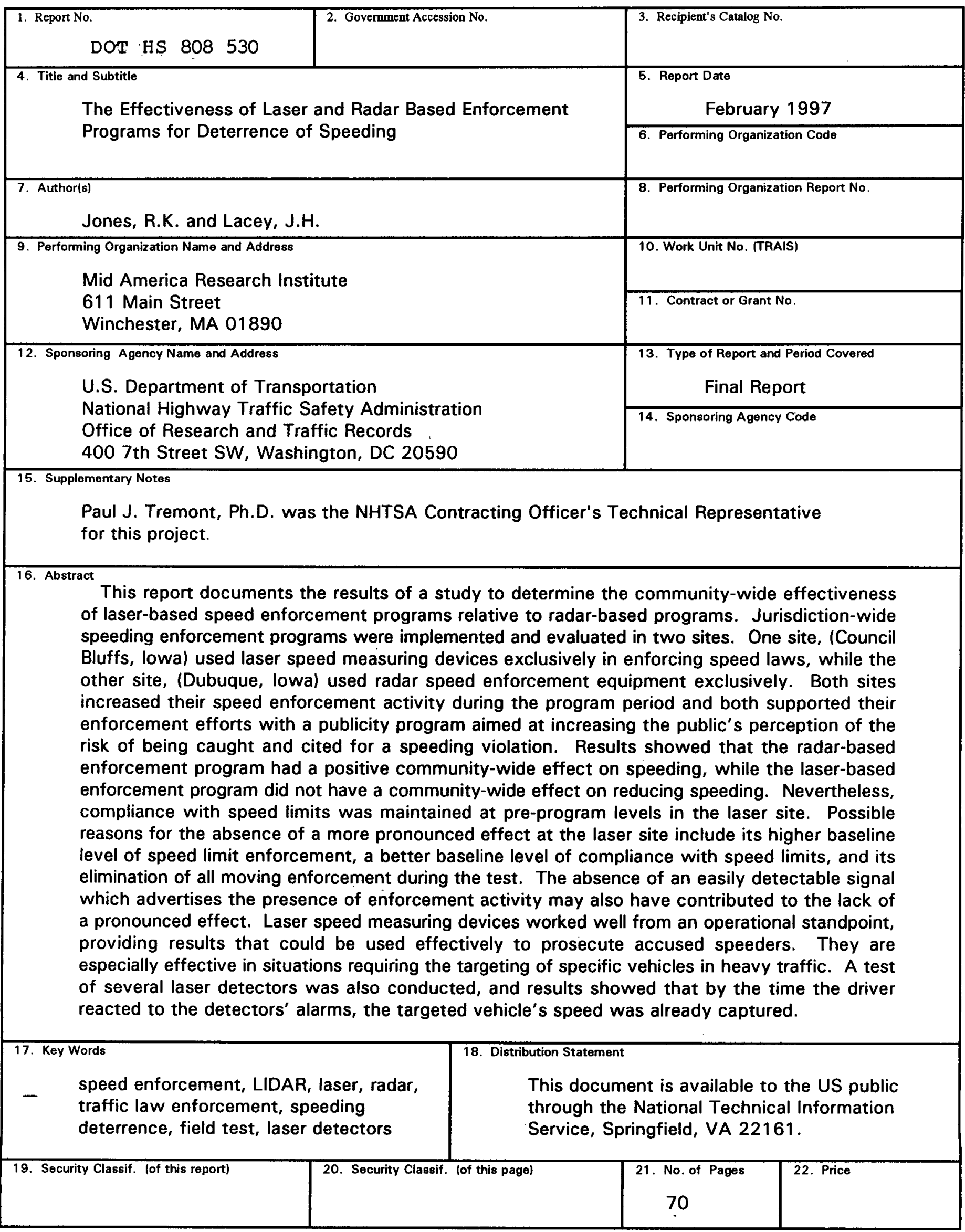




\section{ACKNOWLEDGMENTS}

The authors wish to thank several individuals who were pivotal to the successful completion of this project.

Mr. Mark Campbell of the Iowa Governor's Traffic Safety Bureau was instrumental in identifying and recruiting the test sites and facilitating their participation throughout the project. Mr. Terry Dillinger, Director of the Office of Driver Services in the Iowa Department of Transportation, coordinated implementation of the driver surveys.

In Council Bluffs, Captain Lindsay E. Anderson and Lieutenant Michael J. Terry, planned and executed enforcement, publicity and data collection activities. In Dubuque, Captain William J. Gravatt and Lieutenant Larry C. Verdick admirably performed those duties. Their efforts and those of the many patrol officers in both jurisdictions who so effectively enforced the speed laws are greatly appreciated.

We are most grateful to Sheriff J. Al Cannon, Jr. of Charleston County, South Carolina for the help provided by his Selective Traffic Enforcement Unit in the preliminary test of laser detectors documented in this report. We appreciate the spirit of cooperation and the high degree of professionalism exhibited by all of the officers who participated. These officers were: Lt. Richard Allen, Commander of Selective Traffic Enforcement, Deputy Dennis Bailey, Deputy Michael Rohaus, Deputy Robert Newton, Deputy George Karges, and Deputy Thomas Glovier. 


\section{TABLE OF CONTENTS}

ACKNOWLEDGMENTS $\ldots \ldots \ldots \ldots \ldots \ldots \ldots \ldots \ldots$ iii

EXECUTIVE SUMMARY $\ldots \ldots \ldots \ldots \ldots \ldots \ldots \ldots \ldots \ldots$ ix

1. INTRODUCTION $\ldots \ldots \ldots \ldots \ldots \ldots \ldots \ldots \ldots \ldots \ldots \ldots$

OBJECTIVES $\ldots \ldots \ldots \ldots \ldots \ldots \ldots \ldots \ldots \ldots \ldots \ldots \ldots \ldots \ldots \ldots \ldots \ldots \ldots \ldots$

GENERAL APPROACH $\ldots \ldots \ldots \ldots \ldots \ldots \ldots \ldots \ldots \ldots \ldots$

2. PROGRAM DESCRIPTION $\ldots \ldots \ldots \ldots \ldots \ldots \ldots \ldots \ldots$

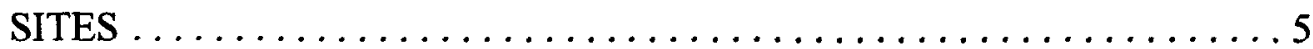

Enforcement Program Related Criteria .............. 5

Publicity Program Related Criteria . . . . . . . . . . . . . 6

Comparability Criteria $\ldots \ldots \ldots \ldots \ldots \ldots \ldots \ldots \ldots \ldots \ldots \ldots \ldots \ldots \ldots \ldots$

Site Selection $\ldots \ldots \ldots \ldots \ldots \ldots \ldots \ldots \ldots \ldots \ldots \ldots \ldots$

THE SPEED ENFORCEMENT PROGRAMS $\ldots \ldots \ldots \ldots \ldots \ldots \ldots$

Enforcement Activity $\ldots \ldots \ldots \ldots \ldots \ldots \ldots \ldots \ldots \ldots \ldots \ldots \ldots \ldots \ldots \ldots$

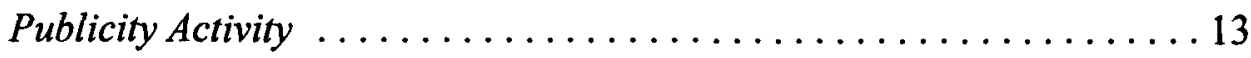

DATA COLLECTION $\ldots \ldots \ldots \ldots \ldots \ldots \ldots \ldots \ldots \ldots \ldots \ldots \ldots \ldots \ldots \ldots \ldots$

3. PROGRAM EVALUATION $\ldots \ldots \ldots \ldots \ldots \ldots \ldots \ldots \ldots \ldots$

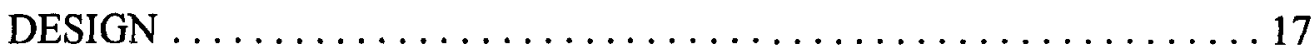

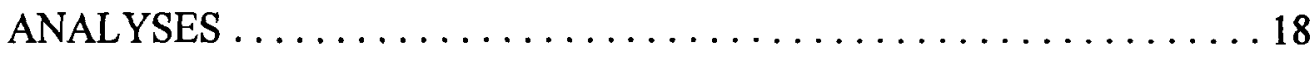

Within-Community Effects ...................... . 19

Vehicle Speeds ....................... 19

Laser (Council Bluffs) . . . . . . . . . . . . . 21

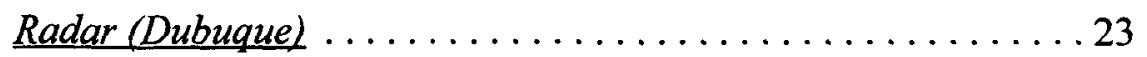




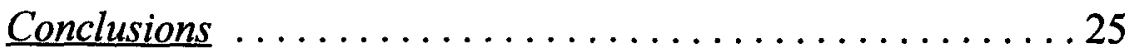

Enforcement Awareness and Enforcement Activity ...........25

Radar (Dubuque) $\ldots \ldots \ldots \ldots \ldots \ldots \ldots \ldots \ldots \ldots . \ldots \ldots$

Laser (Council Bluffs) $\ldots \ldots \ldots \ldots \ldots \ldots \ldots \ldots \ldots 28$

Between-Community Effects ........................29

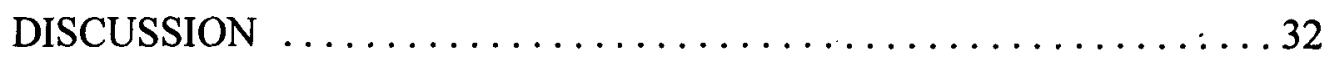

4. CONCLUSIONS AND RECOMMENDATIONS $\ldots \ldots \ldots \ldots \ldots \ldots, \ldots \ldots$

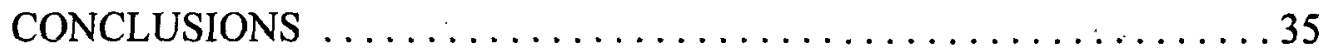

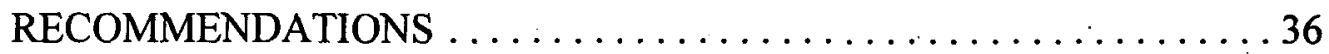

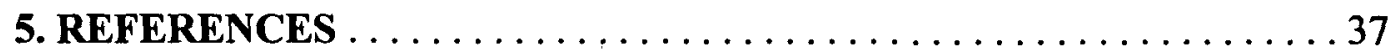

APPENDIX A - PHASE 1 RESULTS $\ldots \ldots \ldots \ldots \ldots \ldots \ldots \ldots \ldots \ldots$

TEST OBJECTIVE AND APPROACH $\ldots \ldots \ldots \ldots \ldots \ldots \ldots \ldots \ldots$

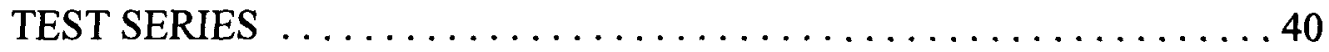

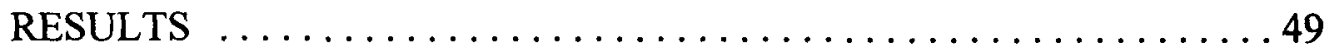

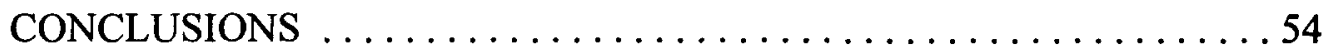

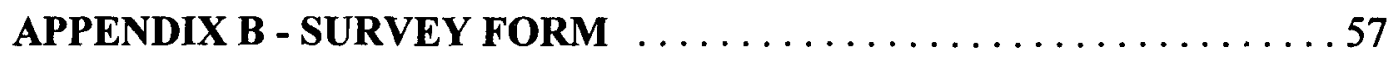




\section{FIGURES}

Figure 3-1: Speeding Citations in Dubuque, 1993-1995 ............ 27

Figure 3-2: Speeding Citations in Council Bluffs, 1992-1995 . . . . . ...29

Figure 3-3: 85th Percentile Speed $\ldots \ldots \ldots \ldots \ldots \ldots \ldots \ldots \ldots \ldots \ldots \ldots \ldots$

Figure 3-4: Percent Over Limit $\ldots \ldots \ldots \ldots \ldots \ldots \ldots \ldots \ldots \ldots \ldots \ldots$

Figure 3-5: Percent 5+ MPH Over Limit .................. 31

Figure 3-6: Percent 10+ MPH Over Limit .................... 31

Figure 3-7: Unadjusted Means of Three Speed Measures in the Two Study Communities (Data From Entire Study Period) .............. 32

Figure A-1: Illustration of Static Test Configurations (Series 1) $\ldots \ldots .42$

Figure A-2: Diagram of Setup for Series 2 Tests $\ldots \ldots \ldots \ldots \ldots \ldots . \ldots 4$

Figure A-3: Diagram of Setup for Series 3 Tests $\ldots \ldots \ldots \ldots \ldots \ldots 46$

Figure A-4: Diagram of Setup for Series 4 Tests $\ldots \ldots \ldots \ldots \ldots \ldots 48$ 


\section{TABLES}

Table 2-1: Enforcement Schedule - Council Bluffs - Laser . . . . . . . . 10

Table 2-2: Enforcement Schedule - Dubuque - Radar ............ 11

Table 3-1: Measured / Observed Variables for Speed Analyses ........ 18

Table 3-2: Derived Variables Used in the Analyses $\ldots \ldots \ldots \ldots \ldots \ldots 18$

Table 3-3: Speed Measures by Phase, Laser Site - Analysis at the Session Level

Table 3-4: Phase Odds Ratios for Laser-Site Speed Variables $\ldots \ldots \ldots 23$

Table 3-5: Calculated Probabilities in Percentage of Three Speed Outcomes at the Laser Site by Program Phase $\ldots \ldots \ldots \ldots \ldots \ldots \ldots \ldots \ldots \ldots \ldots$

Table 3-6: Speed Measures by Phase, Radar Site - Analysis at the Session Level 24

Table 3-7: Phase Odds Ratios for Radar-Site Speed Variables ......... 25

Table 3-8: Calculated Probabilities in Percentage of Three Speed Outcomes at

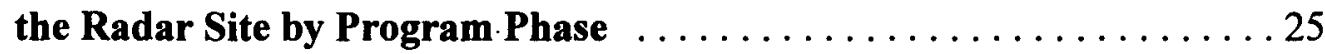

Table A-1: Detector Make Code vs. Response $\ldots \ldots \ldots \ldots \ldots \ldots \ldots$ 


\section{EXECUTIVE SUMMARY}

\section{PURPOSE}

Speeding has long been recognized as a traffic-safety problem. Speed limit laws are usually enforced by police personnel in police vehicles relying almost entirely on observation assisted by technology. At this writing, radar measurements of vehicle speeds are widely used, although more police agencies are procuring laser speed measurement devices. This report documents the results of a study to determine the community-wide effectiveness of laser-based speeding programs relative to radarbased programs. Information regarding the sites, program descriptions and program evaluations is included.

\section{METHODS}

Community-wide speed enforcement programs were implemented and evaluated in two sites. One site (Council Bluffs, Iowa) used laser speed measurement devices (LSMD) entirely in enforcing speed laws, while the other site (Dubuque, Iowa) used only radar speed measurement devices (RSMD). Both sites increased their speed enforcement activity during the program period and supported their enforcement effort with a publicity program aimed primarily at increasing the public's perception of the risk of being caught and cited for a speeding violation.

The two enforcement programs were evaluated on the basis of their communitywide effect on speeding. Speeds were measured once each week at 10 locations in each site during the baseline period and the program period. The locations were selected to provide a range of traffic conditions in each site. Speed measurements were made by LSMDs operated by trained observers located in unobtrusive civilian vehicles. The evaluation compared speeds at the laser site to those at the radar site during the baseline and enforcement-program periods. 
The speed measurements were supplemented by data gathered in surveys of licensed drivers at Department of Motor Vehicles offices. The surveys measured the respondents' awareness of program publicity, their perceptions of enforcement activity and risk, and their (self-reported) speeding behavior. Process data in the form of speeding citations and a log of publicity activities were also collected.

\section{FINDINGS}

The evaluation showed that the radar-based speed enforcement program in Dubuque, lowa had a positive community-wide effect on speeding, decreasing the percentage of vehicles traveling 5 and $10 \mathrm{mph}$ or more over the posted speed limit by about $20 \%$ each.

The laser-based enforcement program in Council Bluffs, Iowa did not have a community-wide effect in reducing speeding. However, speed limit compliance was maintained at pre-program levels. The absence of any speed reductions in the laser site may have been influenced by the following:

- a higher baseline level of speed limit compliance in the laser community than in the radar community,

- a higher baseline level of speed limit enforcement in the laser community than in the radar community, and

- the replacement (as required by the experimental design) of a prior enforcement strategy using moving vehicles for detecting speed violators.

It is also possible that some of the reduction in speeding at the radar site may be attributable to the use of a measuring device that creates an easily-detectable signal (radar) in a concentrated program of enforcement activity. If so, it would follow that because they do not create a widely-dispersed, easily-detectable electromagnetic signature, laser-based speed measuring devices would have an inherently lower deterrent effect than do radar-based speed measuring devices. If this is so, publicity is critical to speed enforcement programs that rely on the use of lasers. 
The laser speed measuring devices performed well from an operational standpoint, providing results that could be used effectively in prosecuting accused speeders. A preliminary field test of laser detectors conducted as a part of this project demonstrated that laser detectors responded to a laser speed measuring device targeted directly at the detector-equipped vehicle, but by the time driver reacted to the detector's warning signal, his or her pre-braking speed was already captured.

The study suggested that laser speed measuring devices might be better suited to augmenting rather than replacing existing radar speed measuring devices. Under some conditions of traffic flow and terrain, radar might be preferable to lasers. The very fact that radar use is detectable by vehicles not targeted might enhance its effectiveness as a deterrent. The study recommends that laser speed measuring devices should be considered for use in situations where vehicle targeting is critical, for example, measuring the speed of a vehicle in a congested stream of traffic. Radar speed measuring devices, with their widespread and easily-detected signal, should be considered for general-purpose use. 


\section{INTRODUCTION}

\section{BACKGROUND}

The major strategy used in managing the traffic-crash risk created by speeding has been to pass speeding laws and to have law enforcement agencies enforce these laws. This means that law violators must be detected and caught, both for specific deterrence and, in theory, for general deterrence as well. Speed limit laws are usually enforced by police personnel in police vehicles relying almost entirely on observation assisted by technology. That technology, at present, is primarily radar-measurement of vehicle speeds.

Speed measurement devices must meet a number of requirements in order to be effective. These include accuracy, ability to discriminate targets from other vehicles in the traffic stream, operational practicality, and resistance to defeat by motorists' countermeasures.

The inherent limitations of radar in meeting some of these requirements have led to the application of a relatively new technology, laser speed measurement. This technology has, from its inception, offered great promise for traffic-safety applications, and is now being offered by manufacturers for operational use by enforcement agencies. Theoretically, because of their narrow beam width (less than $1 / 2$ degree), laser speed-measurement devices (LSMDs) are inherently more accurate, have higher target discrimination capability, and are more difficult to defeat than are radar speed measuring devices.

With respect to the effectiveness of speeding enforcement programs on vehicle speeds, nearly all evaluative research on speeding enforcement has dealt with the effects of various strategies (usually employing radar) in the vicinity of the enforcement team. Such research has shown convincingly that very significant reductions 
of speeding can be obtained for distances up to several miles by various techniques (Joscelyn, Jones, and Elston, 1970; Joscelyn, Bryan, and Goldenbaum, 1971; Jones et al., 1980). A study by Teed, Lund, and Knoblauch (1991) found that speed reductions could also be achieved in the vicinity of an active radar device without the presence of a police symbol.

Oddly enough, there has been very little research into the effectiveness of community-wide, general-deterrence speed enforcement programs on speeding. A recent NHTSA-sponsored study of the enforcement of speeding combined with the enforcement of DWI and non-use of seatbelts, sought information about communitywide speeding enforcement programs, but found no documentation (or even any evidence) of such programs or evaluations (Jones et al., 1995). However, one of the sites (Chattanooga, Tennessee) in the combined-enforcement project implemented an intensive radar-based speed enforcement campaign supported by a PI\&E effort. An evaluation of the Chattanooga campaign revealed an $8 \%$ reduction in the percentage of vehicles exceeding the speed limit by at least $10 \mathrm{mph}$ at eight different locations during times of no speed enforcement activity. Data collected subsequent to the end of the project indicated the speed reductions continued for another year (Jones and Lacey, in press).

We know of no similar studies of the community-wide effect of laser-based speeding enforcement programs on measured speeds, nor have we found any comparisons of the community-wide effect of laser-based enforcement relative to radar-based enforcement. ${ }^{1}$ This report documents the findings of field tests designed to estimate the relative effectiveness of LSMDs in deterring speeding throughout the jurisdiction of a local enforcement agency.

\footnotetext{
- Studies of other aspects of laser and radar use in speeding enforcement have been conducted. For example, Teed and Lund (1993) studied the local effects of laser speed-measuring devices and radar speed-measuring devices on the efficiency of ticketing speeders. They found that more tickets could be written under laser enforcement than under radar enforcement.
} 


\section{OBJECTIVES}

This project was concerned with the community-wide effects of speeding enforcement programs. The general objective of the project was to measure the general-deterrent effect of laser speed-measurement programs relative to that of radar speed-measurement programs. Specific objectives of the project were:

1. to assess whether laser speed measurement devices (LSMDs) can operate effectively in a laser-detector environment;

2. to determine the community-wide effectiveness of laser-based speed enforcement programs relative to radar-based programs to deter speeding; and

3. to determine the community-wide effect of special-applications laser-based speeding programs relative to radar-based programs.

The present report is concerned with the first and second of these specific objectives which were accomplished during Phase 1 and Phase 2 of the project respectively. Phase 1 showed that LSMDs can operate effectively in a laser-detector environment of the type that existed during the time of the test. Results of Phase 1 are summarized in Appendix A of this report. A second report addressing objective 3 will be published at a later date.

\section{GENERAL APPROACH}

Community-wide speeding enforcement programs were implemented, operated, and evaluated in two sites. One site (Council Bluffs, Iowa) used laser speed measurement devices (LSMD) entirely in enforcing speed laws, while the other site (Dubuque, Iowa) used only radar speed measurement devices (RSMD). Both sites increased their speed enforcement activity during the program period and both 
supported their enforcement efforts with a publicity program aimed primarily at increasing the public's perception of the risk of being caught and cited for a speeding violation.

The program period was segmented into two parts, (1) enforcement without publicity and (2) enforcement with publicity. Part 1 ran from November, 1994 to mid-January, 1995, and Part 2 ran from mid-January, 1995 through April 30, 1995. In Part 2 , the publicity component was added at both sites. In addition, there was a pre-program or baseline period extending from September, 1994 through October, 1994. In Part 1, both sites operated the enforcement part of their program, but did so without any publicity. The two enforcement programs were evaluated on the basis of their jurisdiction-wide effect on speeding and by surveys of licensed drivers.

Speeds were measured once each week at 10 locations in each site during a period encompassing the baseline period and the program period for a total of approximately 50,000 measurements at each site. The locations were selected to provide a range of traffic conditions in the sites. Speed measurements in both sites were made by LSMDs operated by trained observers located in unobtrusive civilian vehicles. There was no speeding enforcement activity when speeds were being measured at a given location. The evaluation compared speeds at the laser site with those at the radar site to see if there were any differential changes over the baseline and program periods that could be attributed to the enforcement programs.

The surveys measured the respondents' awareness of program publicity, their perceptions of enforcement activity and risk, and their self-reported speeding behavior. Process data in the form of speeding citations and a log of publicity activities were also collected.

The data were analyzed using several statistical procedures which controlled for factors such as speed limit, traffic volume, weather, road surface, time of day, and day of the week. These factors could have influenced speeds differentially at the two sites and confounded the results. 


\section{PROGRAM DESCRIPTION}

SITES

Criteria relating to both enforcement and publicity campaigns were used in selecting sites for the Phase-2 study.

\section{Enforcement Program Related Criteria}

Criteria relating to enforcement included:

Willingness of police to cooperate. This included the willingness to adhere to the experimental design, which specified introducing a speed enforcement effort of increased intensity in accordance with agreed procedures over a period of about 10 months. It also included the willingness to provide personnel and equipment needed for the enforcement efforts. An additional requirement was specified for the laser site: the department was to replace all radar enforcement with laser enforcement (including moving radar enforcement).

Conditions justifying speed enforcement. If road conditions and / or speed limits are such that speeding is rare, a speed-enforcement program which places much emphasis on speed enforcement would probably not be very effective. We had to confirm that speeding was a significant traffic safety problem in the candidate sites (see below).

Availability of data. This included citation data for a period of at least two years prior to implementation of the program. It also included the capability of conducting an independent attitudinal survey on issues related to the project. Legal environment. Both the statutory law and judicial decisions had to be supportive of the use of laser equipment and radar equipment in the enforcement 
of speeding laws. For example, some jurisdictions had attempted to implement laser speed enforcement only to have judges not accept the evidence obtained by LSMDs on the grounds that the technology had not been proven.

\section{Publicity Program Related Criteria}

Site selection criteria critical to the supporting publicity effort included: Willingness of city management to cooperate in the Program. This criterion was critical to the establishment of a community-based publicity program. Willingness of local police agencies to make a true commitment to the program. This included the willingness on the part of the chief(s) to give the project high priority, to make resources available for making this a real and permanent initiative, and to take an active role in both the enforcement and public information activities.

Availability of an effective police-based local coordinator. The potential for success of this type of publicity program is strongly related to the effectiveness of the local coordinator. The ability to work well with the public, the media, and the departments cooperating in the program was essential. This task is best handled by a person based within the enforcement agency. Ideally, this person should be an operations officer who adapts easily to conducting publicity efforts or should be a public information officer with an understanding of police operations.

Ability to develop widespread local ownership and resources. Because this project had only a small amount of funding available for materials and promotions, it was necessary to choose a site that had adequate resources (such as the support of local businesses, industry and volunteer and civic groups) available to supplement the law enforcement agencies' efforts.

Availability of local media. Local television and radio stations, newspapers and other media outlets were necessary to getting the messages out to the driving 
public. It was important that the media be agreeable to "metering" news about the program so that future activities would not be compromised before the formal introduction of a program element.

\section{Comparability Criteria}

Comparability of the laser and the radar sites. It was preferred that both sites be from the same state, since confounding factors (such as differences in laws) can make a comparison of sites in different states quite uncertain. Characteristics that should be similar in the two sites include:

- level of command emphasis of speed-law enforcement and general approach to speed-law enforcement,

- general social and economic characteristics,

- historic accident patterns and trends,

- general mix of roadway types, and

- general severity of speeding problem.

\section{Site Selection}

Several site pairs that appeared to meet these criteria were identified. Visits were made to one site pair expressing interest to establish that local enforcement personnel were willing to implement the selected enforcement strategies, that existing data met project requirements, and that an enthusiastic local contact person really was available to support the publicity effort.

Ultimately, two cities in Iowa, Council Bluffs and Dubuque, were selected. Neither city had been using LSMDs, and each had a population of about 60,000 . These two cities are quite similar in many respects. Both are river towns and each forms a distinct entity without any contiguous towns. Council Bluffs is on the 
Missouri River on the western side of Iowa, and Dubuque is on the Mississippi River on the eastern side of Iowa. This physical separation of the two sites virtually eliminated the chances of any cross-contamination of the programs. The two cities were also comparable demographically, having similar racial mixtures and income levels. Both had about the same size police departments ( $\sim 100$ persons); both had similar size traffic units; and both placed higher than average emphasis on traffic enforcement. Both cities were willing to cooperate in putting together programs that would be comparable in intensity and phasing.

Each city was agreeable to become either the laser or the radar site, but Council Bluffs appeared better suited to the use of LSMDs because it has more open terrain and is flatter. Also, the Council Bluffs Police Department was willing to replace its radars with LSMDs. Thus, Council Bluffs became the laser site and Dubuque the radar site.

\section{THE SPEED ENFORCEMENT PROGRAMS}

\section{Enforcement Activity}

The enforcement schedule for Council Bluffs is shown in Table 2-1. The cells of the table indicate which of five sections of the city were targeted for intensive enforcement during which period (morning or afternoon) of a given day of a given week. Five such sections were subjected to rotating enforcement using LSMDs. The sections were:

Section 1: An area west of 8th street and north of Highway 6 .

Section 2: An area east of 8th street, south of Highway 6, and north of I-80.

Section 3: An area west of 8th street, south of Highway 6, and north of 23rd Avenue.

Section 4: An area east of 8th street and north of Highway 6. 
Section 5: An area south of 23rd Avenue east from the Missouri River to the South Expressway, then south of 1-80 to the eastern city limits.

As indicated in the table, the intensive enforcement "blitz" was concentrated into either morning or afternoon sessions, with one or more teams deployed throughout the target section. Up to five LSMDs units were deployed simultaneously in a given section as determined by department management staff. Tactics ranged from oneperson units performing both detection and apprehension functions, to units consisting of one detection officer and multiple apprehension officers. Stationary measurement methods were used at all times. In addition, traffic unit officers were available during non-blitz hours to respond to specific problems.

The enforcement schedule for Dubuque is shown in Table 2-2. The layout is similar to that of the table for Council Bluffs, except that (1) the targeted areas for Dubuque are called sectors rather than sections and (2) there were six such sectors in Dubuque rather than the five sections in Council Bluffs. The six sectors were subjected to rotating enforcement using radar speed measuring devices (RSMDs). The six sectors were:

Sector 1: Downtown 101

Hwy. 151-61 (E. 16th to Grandview Overpass)

White St. (400-700 Blks) (1500-1800 Blks)

Bluff St. (200-300 Blks)

E. 11 th St. (East of Jackson)

Locust St. (South of Dodge)

Sector 2: Industrial 102

Peru Rd.

Kerper Blvd.

Windsor Ave.

Lincoln Ave.

Rhomberg Ave.

Shiras Ave.

Roosevelt St.

E. 16th (both E. \& W. of Kerper) 
Table 2-1: Enforcement Schedule - Council Bluffs - Laser

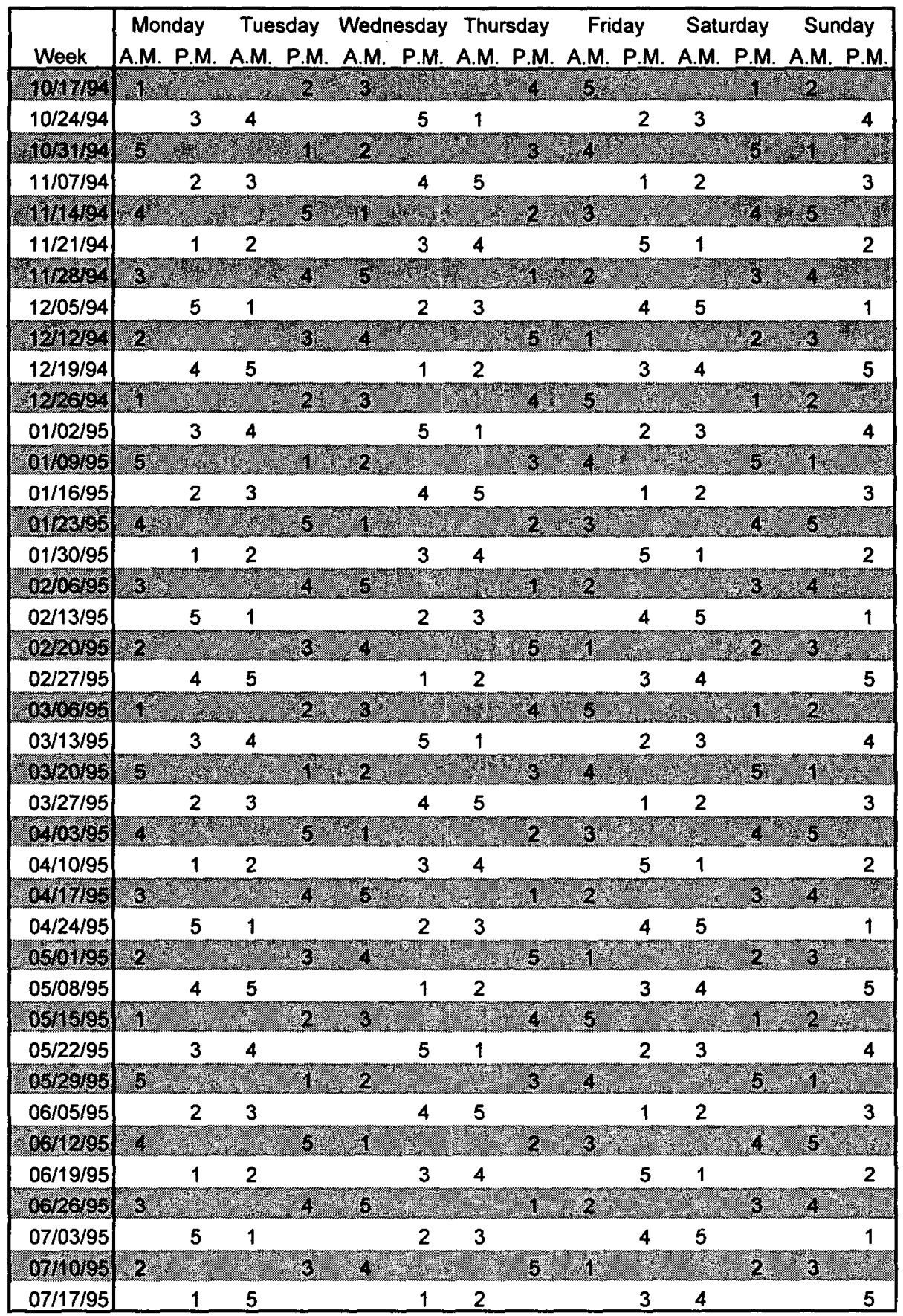


Table 2-2: Enforcement Schedule - Dubuque - Radar

\begin{tabular}{|c|c|}
\hline Week & 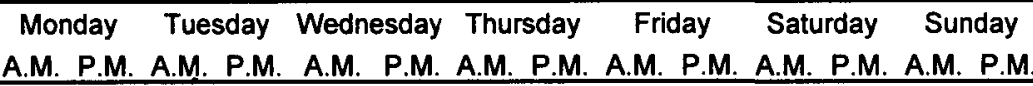 \\
\hline $11 / 21 / 94$ & 2 \\
\hline 8 & \\
\hline $12 / 05 / 94$ & 3 \\
\hline 2412,64 & 4 \\
\hline $12 / 19 / 94$ & 2 \\
\hline 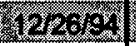 & 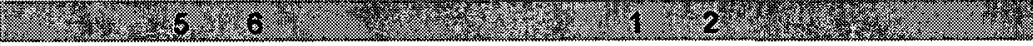 \\
\hline $01 / 02 / 95$ & 6 \\
\hline $01 \log 95$ & 6 \\
\hline $01 / 16 / 95$ & 2 \\
\hline 010505 & 5 \\
\hline $01 / 30 / 95$ & 2 \\
\hline 026.65 & $\sqrt{2}$ \\
\hline $02 / 13 / 95$ & 5 \\
\hline 022095 & 2 \\
\hline $02 / 27 / 95$ & 2 \\
\hline 83 & 6 \\
\hline $03 / 13 / 95$ & 6 \\
\hline 052065 & 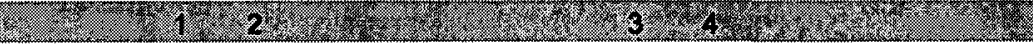 \\
\hline $03 / 27 / 95$ & 6 \\
\hline (1) & 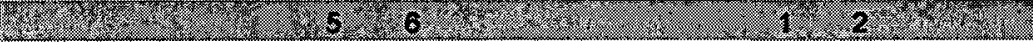 \\
\hline $04 / 10 / 95$ & 5 \\
\hline 0417195 & $4 x^{2}+2$ \\
\hline $04 / 24 / 95$ & 2 \\
\hline 050108 & 1 \\
\hline $05 / 08 / 95$ & 2 \\
\hline 0.5505 & 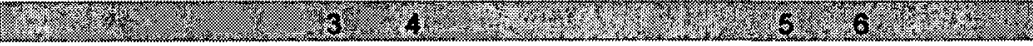 \\
\hline $05 / 22 / 95$ & 3 \\
\hline 05120165 & 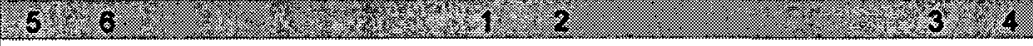 \\
\hline $06 / 05 / 95$ & 2 \\
\hline $06 \sqrt{1215}$ & 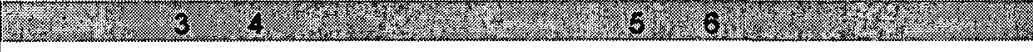 \\
\hline $06 / 19 / 95$ & 5 \\
\hline 0.5126105 & $27-12=20$ \\
\hline $07 / 03 / 95$ & 1 \\
\hline 071005 & 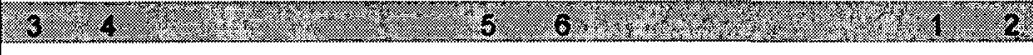 \\
\hline $07 / 17 / 95$ & 5 \\
\hline
\end{tabular}


Sector 3: Northend 103

Clarke Dr.

Kane St.

W 32nd St. (E of Grandview)

Kaufmann Ave.

W Locust

Wahlert HS Area

Senior HS Area

Sector 4: North Hill 104

Carter Rd.

W 32nd St. (W of Grandview)

Kaufmann (Maryville Area)

Pennsylvania Ave.

Hillcrest Rd.

NW Arterial (N of Penn to W 32nd)

Asbury Rd. (W of JFK)

Hempstead HS Area

Sector 5: South Hill 105

Cedar Cross Rd.

Fremont Ave.

Kelly Lane

Rockdale Rd.

Hwy. 151-61 (South of Grandview Overpass)

Dodge St. (W of Grandview)

S. Grandview

NW Arterial (S of Penn)

Sector 6: Central Hill 106

Kaufmann Ave. (Maryville Area)

Loras Blvd.

W Locust St.

Senior HS Area

Dodge St. (E of Grandview)

Again, the intensive enforcement effort was concentrated into either morning or afternoon sessions, with one or more teams deployed throughout the target sector. Typically, one to two units operated simultaneously in a given sector, with a given 
unit consisting of (1) a single officer performing both detection and apprehension functions, or (2) two officers, one performing detection and the other performing apprehension. At least monthly, an all-out blitz was conducted in a sector with units consisting of multiple detection officers and multiple apprehension officers.

\section{Publicity Activity}

The publicity programs in the two communities were comparable, except that the content was appropriate to radar detection devices in Dubuque, and to laser detection devices in Council Bluffs. A plan was prepared specifying the timing and content of the publicity activities including such elements as kick-off news conferences and press releases. The programs emphasized increased speed enforcement and potential crash reduction.

The publicity programs concentrated on hard news coverage rather than PSAs. Unlike some traffic safety countermeasures, the radar and laser initiatives were of interest to the media, and the publicity programs in both sites exploited hard news coverage.

Elements of the publicity programs included:

- A project launch, covered by local media, announcing command emphasis on speed enforcement. At the laser test site, this included an exhibit of the equipment and a description of its benefits and advantages compared with radar.

- Periodic demonstrations of the laser and radar equipment and use of the equipment in real enforcement situations.

- Press conferences describing program results and public safety benefits. These included the message that the likelihood of being detected has increased as a result of the project. 
In addition to these project-generated hard news items, secondary hard news was generated as a result of the project. Examples of secondary hard news included newspaper and broadcast editorials, radio talk shows, and spin-off newspaper articles about related topics such as safe driving and safe pedestrian behavior.

\section{DATA COLLECTION}

Speed measurement data were collected during weekly sessions at 10 locations at each site by local staff. Each measurement session was approximately one hour in duration and was conducted at times when there was no enforcement activity. Speed measurement data collection was supervised by Mid-America's subcontractor, The Center for Applied Research.

Measurements of individual vehicle speeds, the lane used, and the vehicle type were obtained. In addition, vehicle counts for five minute periods were made to get information on traffic density; weather and road conditions were also recorded periodically. Speed-measurement staff observed only lone vehicles or the first vehicle in a line of vehicles. These vehicles were in freely flowing traffic, and their speeds were not affected by other vehicles. Above all, target vehicles were not arbitrarily selected from the traffic stream. The next available vehicle after recording a measurement was observed, regardless of its type or of how fast or how slowly the vehicle was traveling.

The locations were chosen to represent the range of different speed limits at the site. Also, the speed measurement locations were at places where speeding was recognized by the local police as a problem. In addition, the locations were such that an observation vehicle could be safely parked without being obtrusive or affecting speeds. While speed enforcement was conducted in one site with laser and the other with radar, speed measurements were made using the laser speed measuring devices in both sites. 
The effectiveness of the publicity programs were measured through surveys administered by the Iowa Department of Safety. (A facsimile of the survey form is included as Appendix B.) The surveys measured program awareness, perceived risk of enforcement, and self-reported behavior, using questionnaires filled out by drivers at driver license stations. The awareness component was concerned both with awareness of project messages as disseminated through publicity activities, and with the awareness of the enhanced enforcement activity generated by the project. Perceived enforcement risk dealt with the drivers' perception of the risk of getting ticketed for speeding, and self-reported behavior addressed the drivers' own reports of violating speeding laws.

The surveys were administered twice during each community's speeding program, with the first wave occurring shortly before the programs began, and the second shortly after the programs were completed. A sample size of about 1,000 drivers per site was obtained for each wave. The "before" wave established a baseline for comparison, and the "after" wave measured the awareness achieved by the overall program.

The general operating environment was also monitored at each site for the introduction of possible confounding effects that could make it difficult or impossible to determine whether any changes in effectiveness might be attributed to some factor other than the program. Such confounding effects could be caused by various factors including special conditions that affected the flow and speed of traffic (such as a natural disaster) or new legislation or policies that affected the enforcement and adjudication of speeding violations. 


\section{PROGRAM EVALUATION}

\section{DESIGN}

The study evaluation design called for both programs to be conducted over a 10 month period. This period was broken down into three shorter periods, a baseline period (two months), a period of increased enforcement without publicity (three months), and a period of increased enforcement with publicity (five months). The evaluation sought to determine whether various measures of speeds at 10 representative locations in one community decreased relative to those at 10 representative locations in the other community, and if so, whether that decrease could be attributed to the type of speed-measuring device used.

Data of interest in the evaluation were changes in speeds at the representative locations in the communities, self-reported public awareness and speeding behavior, and self-reported perceived risk of enforcement action for speeding. Speeds were measured over the 10-month period at 10 locations in Council Bluffs and 10 locations in Dubuque. Measurements were made at all 10 locations at least once each week during one-hour measurement sessions.

Measured and observed variables used in the analysis are indicated in Table 3-1, below. Variables derived from these measured and observed variables are shown in Table 3-2. 


\section{Table 3-1: Measured / Observed Variables for Speed Analyses}

\begin{tabular}{lll} 
Variable & \multicolumn{1}{c}{ Definition } & \multicolumn{1}{c}{ Range of Values } \\
\hline & & \\
SITE & City conducting speeding program & 1 (Laser, Council Bluffs); 2 (Radar, Dubuque) \\
LOC & Location of a speed measurement session & 1 to 10 \\
LIMIT & Speed limit at a given location & Posted speed, mph \\
DAY & Day of the week of a speed measurement & 1 to 7 \\
& session & \\
WEATHER & Weather during a speed measurement session & 1 (mostly sunny) to 7 (sleet) \\
ROAD & Road conditions during a speed measurement & 1 (dry) to 5 (ice) \\
& session & \\
TIME & Time of day of a speed measurement session & Military time \\
VEH & Type of vehicle & 0 (unknown) to 9 (truck, not specified) \\
SPEED & Speed of vehicle & Measured speed, mph \\
VOL & Traffic volume & Count \\
DATE & Date of a speed measurement session & Date
\end{tabular}

Table 3-2: Derived Variables Used in the Analyses

- Mean speed (SPDM).

- 85 th percentile speed (SPD85).

- Percent of vehicles exceeding the speed limit (PCTOO).

- Whether a vehicle was or was not exceeding the speed limit (OVOO).

- Percent of vehicles exceeding the speed limit by at least $5 \mathrm{mph}$ (PCTO5)

- Whether a vehicle was or was not exceeding the speed limit by at least $5 \mathrm{mph}$ (OVO5).

- Percent of vehicles exceeding the speed limit by at least $10 \mathrm{mph}$ (PCT10) and whether a vehicle was or was not exceeding the speed limit by at least $10 \mathrm{mph}$ (OV10).

\section{ANALYSES}

The analysis was conducted in two parts, within-community effects and betweencommunity effects. The analysis of within-community effects addressed the following questions:

- Did vehicle speeds decrease in either community?

- Can the decrease be attributed to the enforcement program?

$$
\checkmark \text { Was there an increase in driver awareness of the enforcement? }
$$


$\checkmark$ If driver awareness increased, was the increase consistent with an increase in publicity activities?

$\checkmark$ Was there an increase in perceived enforcement risk?

$\checkmark$ If perceived enforcement risk increased, was the increase consistent with an increase in enforcement activities?

The analysis of between-community effects was concerned with the following additional questions:

- Which speed enforcement program (Laser or Radar) was more effective in reducing various measures of speeding?

- Can the differential effect be attributed to the different enforcement programs?

$\checkmark$ Was there a differential increase in awareness in the right direction?

$\checkmark$ If there was a differential awareness increase, was the increase consistent with a difference in publicity activities?

$\checkmark$ Was there a differential increase in perceived enforcement risk in the right direction?

$\checkmark$ If there was a differential perceived risk increase, was the increase consistent with a difference in enforcement activities?

These two classes of possible effects (within-community and betweencommunity), are discussed separately below.

\section{Within-Community Effects}

Vehicle Speeds. Three statistical analyses were performed to determine whether significant changes in speeds occurred over the three project periods. Analysis 1 used the individual speed-measuring sessions as the unit of analysis. Speeds for the 
individual sessions were normally distributed, with the Shapiro-Wilk statistic in the 0.95 to 0.98 range and associated probability greater than 0.10 . The analysis used the Generalized Linear Model technique as implemented by $\mathrm{SAS}^{\circledR}$ in its procedure, PROC GLM. Variables used in the analysis were:

- Dependent variables - mean speed (mean of the session mean speeds), 85th percentile speed, percent over the speed limit, percent at least $5 \mathrm{mph}$ over the limit, and percent at least $10 \mathrm{mph}$ over the limit.

- Independent variable - phase (0: baseline; 1 : increased enforcement without publicity; and 2: increased enforcement with publicity).

- Other independent variables (covariates) - speed limit, weather, road condition, day of week, time of day, and traffic volume.

The covariates were used to adjust for differences in speeds that might have been due to factors other than the enforcement program.

Analysis 2 used the GLM technique and was similar to analysis 1, but considered only individual speeds (and their logarithms) over all sessions as a dependent variable. Analysis 3 also used the individual speeds as a unit of analysis, but employed the logistic regression technique (SAS PROC LOGISTIC) with 0-1 variables as dependent variables ( 1 for over limit, 0 for not over limit; 1 for $5 \mathrm{mph}$ over limit, 0 for not $5 \mathrm{mph}$ over limit; etc.). Analyses 2 and 3 were conducted to obtain another perspective of the speeds.

Of the three analyses, we prefer the first, but have conducted the other two for those who may have other preferences. In Analysis 1, all data from one session can be combined into one observation with the appropriate values of the independent variables. The mean of the observations, proportion of certain observations, or another desired function of the observation can then be used as the dependent variable. In addition, a weight or standard error derived from the observation can be applied. (We used the reciprocal of the standard error as a weighting factor in our 
analysis, applied through the "weight" statement in the SAS GLM procedure.) If the same type of model is fitted to the individual observations, or to the session means, the same coefficients are obtained.

There are two advantages to using sessions as the unit of analysis: (1) the calculations are usually simple and much faster, and, more important, (2) it is much easier to separate systematic deviations between model and data from pure "noise." Moreover, there is one very serious argument against using individual observations (rather than sessions) in a situation like the present one: the standard models and techniques assume that individual observations or their residuals are independent. It would be very difficult or practically impossible to revise these models to account for independence. In our case, it is very likely that uncontrollable factors create correlations between the observations in each session. For example, the traveling population may vary depending on special events, predicted weather, near holidays, etc. Temporary traffic problems may lead to increased and different traffic, etc. Therefore, the assumption of independence of individual observations should be made only if it is validated by a special analysis.

During preliminary runs it was found that there was no statistically significant difference in any of the above measures of speed with respect to the first two project phases. Speeds in the baseline phase in either community did not differ significantly from those in the enforcement-without-publicity phase. Consequently, these two phases were combined into a single phase (called the baseline phase) for subsequent analyses. The enforcement-with-publicity phase that follows the baseline phase is referred to as the test phase.

Laser (Council Bluffs). Table 3-3 summarizes the results of the GLM analyses using session-level data from 286 sessions (analysis 1 ). The data in the table represent the least-square means of the indicated variables, adjusted for the significant covariates, i.e., speed limit, weather, and traffic volume. The table suggests a small increase in all of the speed measures following introduction of 
enforcement with publicity. However, none of the increases was statistically significant. (The last line in the table contains the $\boldsymbol{p}$ values.)

\section{Table 3-3: Speed Measures by Phase, Laser Site - Analysis at the Session Level}

\begin{tabular}{lrrrr} 
Phase & \multicolumn{1}{c}{ SPD85 } & \multicolumn{1}{c}{ PCT00 } & PCT05 & \multicolumn{1}{c}{ PCT10 } \\
\hline Before & 44.8 & 40.2 & 13.4 & 2.1 \\
After & 45.1 & 40.6 & 13.6 & 2.5 \\
\hline \multicolumn{1}{c}{$p$} & $(0.148)$ & $(0.280)$ & $(0.699)$ & $(0.158)$
\end{tabular}

The GLM analysis of speed at the vehicle level (analysis 2, 46,900 individual speed measurements) found that the adjusted mean speed did not change from the baseline phase to the test phase ( $39.4 \mathrm{mph}$ for both phases).

The logistic regression analysis (analysis 3) developed a model of the probability that the speed of any given vehicle was greater than some specified value. As indicated above, probabilities for three such values were of interest: over the speed limit by any amount, $5 \mathrm{mph}$ over the speed limit, and $10 \mathrm{mph}$ over the speed limit. These probabilities were designated as $\mathrm{P}(00 \mathrm{OV}), \mathrm{P}(05 \mathrm{OV})$, and $\mathrm{P}(10 \mathrm{OV})$, respectively.

We first determined the odds ratio for the variable "phase" for each of the three states: over the limit by any amount, over the limit by at least $5 \mathrm{mph}$, and over the limit by $10 \mathrm{mph}$. The odds ratio for "over the limit by any amount" is interpreted as the odds that a given vehicle is over the limit in the test phase (phase $=1$ ) divided by the odds that a given vehicle is over the limit in the baseline phase (phase $=0$ ). Therefore, an odds ratio of less than 1 is associated with a speed reduction from baseline to "after," and an odds ratio of greater than 1 is associated with a speed increase from baseline to "after."

Table 3-4 shows the odds ratios for the program phase for the laser-site speed variables examined in the logistic regression analysis. The $p$ values for the dependent variables are shown in the last column. Odds ratios are greater than 1 for 
all of the dependent variables, indicating that speeds increased slightly in the test phase.

\section{Table 3-4: Phase Odds Ratios for Laser-Site Speed Variables}

\begin{tabular}{ccc} 
Variable & Odds Ratio & $p$ \\
\hline OV00 & 1.102 & 0.0001 \\
OV05 & 1.106 & 0.0006 \\
OV10 & 1.194 & 0.0045
\end{tabular}

In order to compute values rather than the odds ratios for the three probabilities of interest, it is necessary assume values for the independent variables in the logistic regression model. The independent variables were (in addition to phase) speed limit and traffic volume. We computed the probabilities for mean values of these two variables, $37.8 \mathrm{mph}$ and 40.5 vehicles per hour, respectively, and the results are shown in Table 3-5. The probabilities associated with the three outcomes of interest range from about $2 \%$ for $10+$ mph over the limit to $44 \%$ for any speed over the limit. The probabilities are slightly higher in the test phase.

Table 3-5: Calculated Probabilities in Percentage of Three Speed Outcomes at the Laser Site by Program Phase

\begin{tabular}{lccc} 
& \multicolumn{3}{c}{ Outcome } \\
\cline { 2 - 4 } Phase & Over Limit & $\begin{array}{c}5+\text { mph Over } \\
\text { Limit }\end{array}$ & $\begin{array}{c}\text { 10+ } \\
\text { mph Over } \\
\text { Limit }\end{array}$ \\
\hline Before & 42.0 & 11.7 & 2.1 \\
After & 44.5 & 12.8 & 2.5
\end{tabular}

Radar (Dubuque). The session-level GLM results (analysis 1) are summarized in Table 3-6. Data from 158 speed-measuring sessions were used in the 
analysis. The table indicates a decrease with phase in all of the speed measures except 85th percentile speed, which did not change. The decreases in percent over the limit and percent $5+\mathrm{mph}$ over the limit were fairly large and statistically significant, amounting to 10.4 and 7.3 percentage points, respectively. Percent $10+$ mph over the limit also decreased (by 2.1 percentage points), but the decrease was only marginally significant.

Table 3-6: Speed Measures by Phase, Radar Site Analysis at the Session Level

\begin{tabular}{lrrrr} 
Phase & \multicolumn{1}{c}{ SPD85 } & \multicolumn{1}{c}{ PCT00 } & PCT05 & PCT10 \\
\hline Before & 41.7 & 71.3 & 33.8 & 8.4 \\
After & 40.9 & 60.9 & 26.5 & 6.3 \\
\hline \multicolumn{1}{c}{$\boldsymbol{p}$} & $(0.057)$ & $(0.0001)$ & $(0.002)$ & $(0.079)$
\end{tabular}

The GLM analysis of speed at the vehicle level (analysis 2, 29,823 individual speed measurements) found that the adjusted mean speed decreased from $36.9 \mathrm{mph}$ in the baseline phase to $35.8 \mathrm{mph}$ in the test phase, a small but significant decrease $(p=0.0001)$.

The results of the logistic regression analysis (analysis 3) were consistent with those from the GLM analyses, showing a reduction in all of the measures of speed. All odds ratios were less than 1 and highly significant (Table 3-7). The probabilities associated with the three outcomes of interest ranged from about $4 \%$ for $10+\mathrm{mph}$ over the limit to $72 \%$ for any speed over the limit (Table 3-8). The probabilities were consistently lower in the test phase. 
Table 3-7: Phase Odds Ratios for Radar-Site Speed Variables

\begin{tabular}{ccc} 
Variable & Odds Ratio & $\boldsymbol{p}$ \\
\hline OV00 & 0.630 & 0.0001 \\
OV05 & 0.756 & 0.0001 \\
OV10 & 0.715 & 0.0001
\end{tabular}

Table 3-8: Calculated Probabilities in Percentage of Three Speed Outcomes at the Radar Site by Program Phase

\begin{tabular}{lccc} 
Phase & \multicolumn{3}{c}{ Outcome } \\
\cline { 2 - 4 } & Over Limit & $\begin{array}{r}\text { 5+ mph Over } \\
\text { Limit }\end{array}$ & $\begin{array}{c}\text { 10+ } \\
\text { mph Over } \\
\text { Limit }\end{array}$ \\
\hline Before & 71.8 & 26.0 & 4.8 \\
After & 61.7 & 21.0 & 3.5
\end{tabular}

Conclusions. The analyses indicate a small increase in all measures of speed with phase at the laser site, and a moderate decrease in all measures of speed at the radar site.

At the radar site, measures of greatest interest to speed-law enforcement (percent $5+$ mph over the limit, probability of $5+\mathrm{mph}$ over the limit, percent $10+\mathrm{mph}$ over the limit, and probability of $10+$ over the limit) all decreased some $20 \%$ from the baseline phase to the test phase. It remains to be seen whether it is reasonable to attribute these decreases to the speed-enforcement program. This question is addressed below. 


\section{Enforcement Awareness and Enforcement Activity}

Radar (Dubuque). One would expect that an enforcement program that achieved a general, community-wide decrease in speeding would be accompanied by a public awareness of increased enforcement.

The survey of licensed drivers (see page 15) asked several questions designed to measure awareness of speed enforcement activity, including the risk of getting caught and ticketed for speeding. Question 5 asked if the respondent had noticed any increase in enforcement of speeding laws in the past three months. There was no change in the responses with respect to survey wave $(p=0.442)^{2}$. In wave 1 of the survey (the baseline phase), $49.6 \%$ answered "yes", and in wave 2 (the test phase), $47.0 \%$ answered "yes."

Question 7 asked whether, compared with three months ago, the chances of a speeder getting caught by the police increased, stayed about the same, or decreased. There was a significant decrease with wave in the percentage of respondents reporting the chances of a speeder getting caught had increased in the past three months $(p=0.024)$. In wave $1,46.5 \%$ said that the chances increased, compared to $37.9 \%$ in wave 2 . These results are unadjusted for differences in respondent characteristics occurring between the two waves.

We used the logistic regression technique to adjust for respondent sex (male $=1$, female $=0$ ) and age. Survey wave was treated as a $0-1$ variable with wave 1 assigned the value of 0 and wave 2 assigned the value of 1 . For question 5 , the value 1 indicated an increase in speeding enforcement, and the value 0 indicated no increase in speeding enforcement. This analysis showed that the odds ratio associated with increased speeding enforcement was slightly less than 1 for the variable wave, suggesting a slight reduction in the respondents' perception of increased enforcement activity. However, the decrease was not significant $(p=0.325)$. For question 7 , the value 1 indicated an increase in the chances that a speeder would be caught, and the

\footnotetext{
${ }^{2}$ The $p$ values used in this section were determined using Pearson chi square tests.
} 
value 0 indicated no increase. For this question, the odds ratio for wave was much smaller, indicating a moderate and statistically significant reduction $(p=0.009)$ in the respondents' perception of increased enforcement risk.

These results suggest that drivers in general at the radar site (Dubuque) did not have any increased awareness of speed enforcement during the program period. Additional analyses accounting for possible differences in awareness among those who were and those who were not speeders did not alter this finding. ${ }^{3}$

Nevertheless, speeding enforcement as measured by number of speeding citations did increase in Dubuque during the test period (Figure 3-1). During the baseline period, monthly citations were in the 150-250 range, but jumped to over 500 in the test period, never returning to the baseline period range until well after the end of the speed-enforcement program.

Figure 3-1: Speeding Citations in Dubuque, 1993-1995

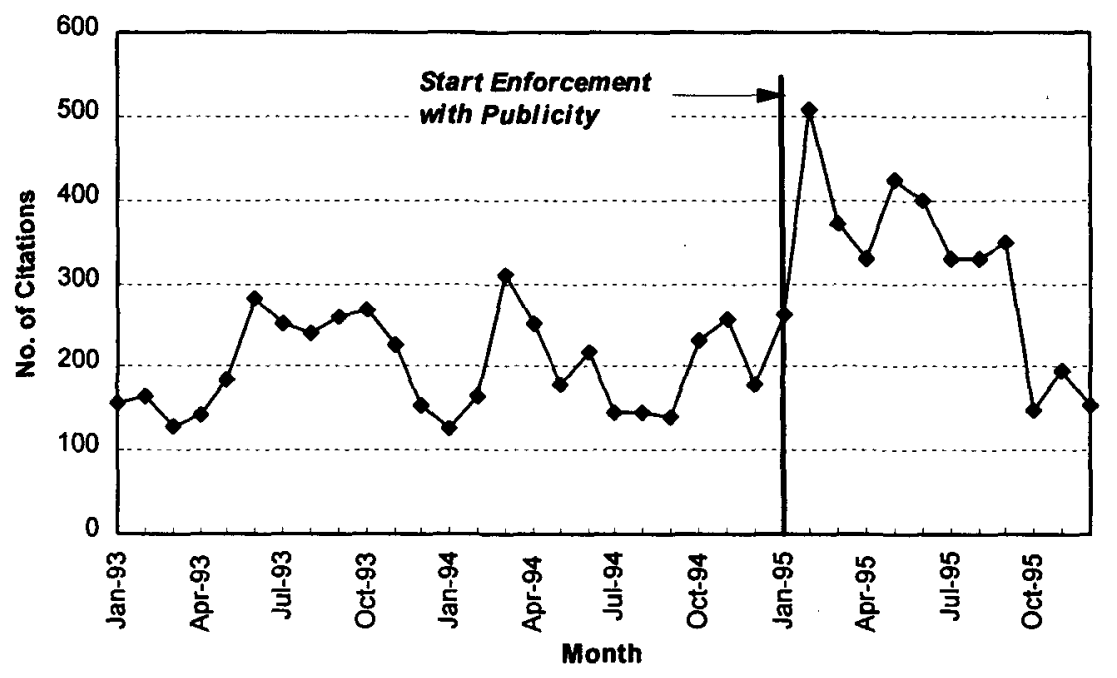

${ }^{3}$ Question 6 of the survey contained a category for "do not speed" which was used to separate speeders from non-speeders. 
A partial explanation for the lack of a conscious awareness of increased speed enforcement was the apparent failure of the Dubuque program to generate any memorable publicity about speeding. The survey of licensed drivers showed that only about $1 \%$ of those responding to either wave recalled having heard, seen, or read any messages about enforcement of laws on speeding in the last three months.

Thus, support for speed data suggesting a program effect in Dubuque is mixed. Clearly, there was a large increase in enforcement activity, but there is no indication from the survey that such an increase was consciously perceived by Dubuque's licensed drivers.

Laser (Council Bluffs). We also examined public awareness of increased enforcement in the Laser site (which did not achieve a general, community-wide decrease in speeding).

The survey showed an increase in the percentage of respondents who had noticed an increase in enforcement of speeding laws in the past three months. In wave 1 of the survey (the baseline phase), $37.2 \%$ noticed an increase, and in wave 2 (the test phase), $54.7 \%$ noticed an increase. The change with respect to wave was significant at the 0.0001 level.

Also, there was a significant increase with wave $(p=0.001)$ in the percentage of respondents reporting the chances of a speeder getting caught had increased in the past three months. In wave $1,35.6 \%$ said that the chances increased, compared to $49.0 \%$ in wave 2 .

As with the laser site, we used the logistic regression technique to adjust for respondent sex (male $=1$, female $=0$ ) and age. This analysis showed that the odds ratio associated with increased speeding enforcement was 1.7 for wave, indicating a fairly large increase in the respondents' perception of increased enforcement activity. The increase was significant $(p=0.0003)$. Further, the odds ratio associated with an increase in the chances that a speeder would be caught was 2.1 for wave, indicating a moderate and statistically significant $(p=0.001)$ increase in the respondents' perception of increased enforcement risk. 
These results suggest that drivers in general at the laser site (Council Bluffs) had an increased awareness of speed enforcement during the program period.

Data on number of speeding citations (Figure 3-2) indicate that the laser site initiated its increased speed enforcement activity some two months before the official start of test period and sustained an increase (with some fluctuations) for some eight months.

Thus, on the surface, neither the awareness data nor the speeding-citations data are consistent with the speed data suggesting no program effect at the laser site. One possible explanation for this apparent inconsistency lies in the nature of the traffic flow at the laser site. The laser site was Council Bluffs, Iowa, which lies just across the Missouri river from Omaha, Nebraska. While the awareness data were gathered from Council Bluffs residents, much of the traffic on Council Bluffs roadways consists of vehicles driven by Omaha residents. There is also considerable Interstate Highway traffic in Council Bluffs, much of which also does not involve drivers from Council Bluffs. Thus, while the population surveyed was aware of increased speedenforcement activity, a large percentage of the drivers using the roadways may not have been and continued to speed.

Figure 3-2: Speeding Citations in Council Bluffs, 1992-1995

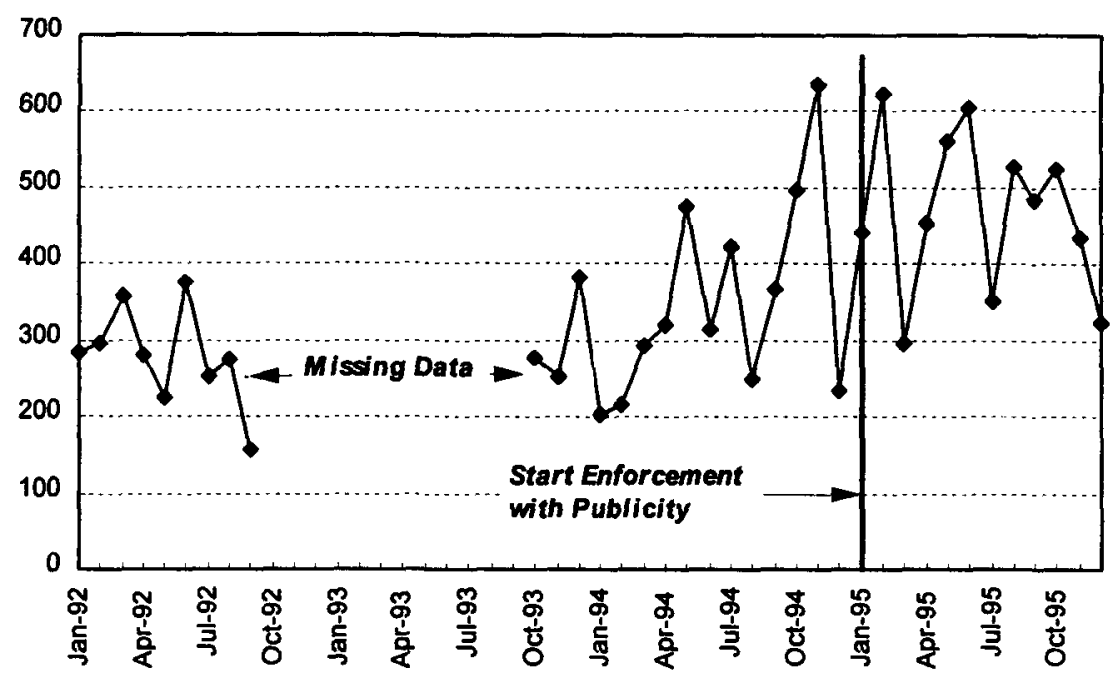




\section{Between-Community Effects}

The above analyses of the within-community effects of the speed enforcement programs indicated a general decrease of speeding in the radar site (Dubuque) and no change or a small increase in the laser site (Council Bluffs). The question addressed here is whether the relative decrease in Dubuque suggested by the withincommunity analyses would remain when adjusted for the differences in road conditions, weather, speed limits, etc. that existed at the two sites.

The analytic approach used to explore this question was similar to that used in the general linearized model (GLM) analyses of the within-community effects. The models used here differed from those used in the prior analyses in that the betweencommunity models included a term for a site-phase interaction effect. We looked for a significant interaction effect such that speeds in Dubuque decreased more in the test phase than did speeds in Council Bluffs.

The results of the analyses of session-level data are depicted graphically in Figure 3-3 through Figure 3-6. The numbers differ from those in prior tables for the within-community effects because the numbers in the figures are for the interaction effects and control for factors that may be different in the two sites, for example, road condition, weather, and speed limit. All of the interaction effects shown were statistically significant ${ }^{4}$. There was a reduction in all measures of speeding in the test phase in the radar site (Dubuque), and an increase or no change in those measures in the laser site (Council Bluffs). The analyses of data at the vehicle level indicated that the mean speed also decreased slightly in the Dubuque radar site (from $37.7 \mathrm{mph}$ to $36.4 \mathrm{mph}$ ) while remaining constant at $37.6 \mathrm{mph}$ in the Council Bluffs laser site.

${ }^{4} p=0.0009$ for the 85 th percentile speed, 0.0001 for percent over the limit, 0.0001 for $5+\mathrm{mph}$ over the limit, and 0.0004 for $10+\mathrm{mph}$ over the limit. 
Figure 3-3: 85th Percentile Speed

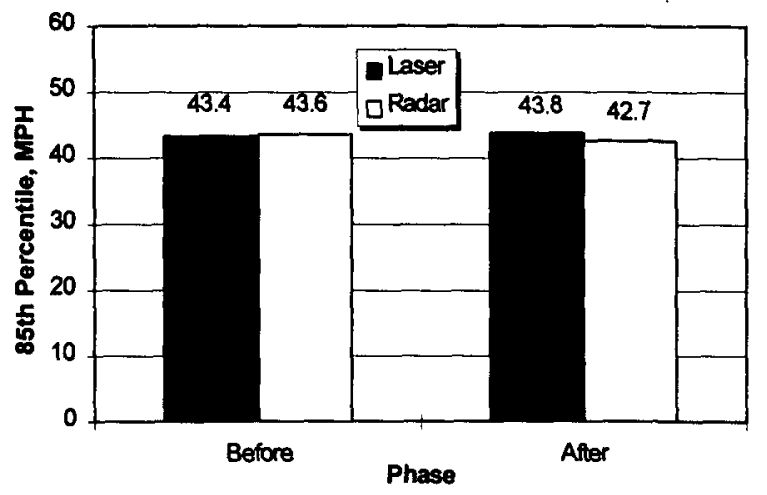

Figure 3-5: Percent 5+ MPH Over Limit

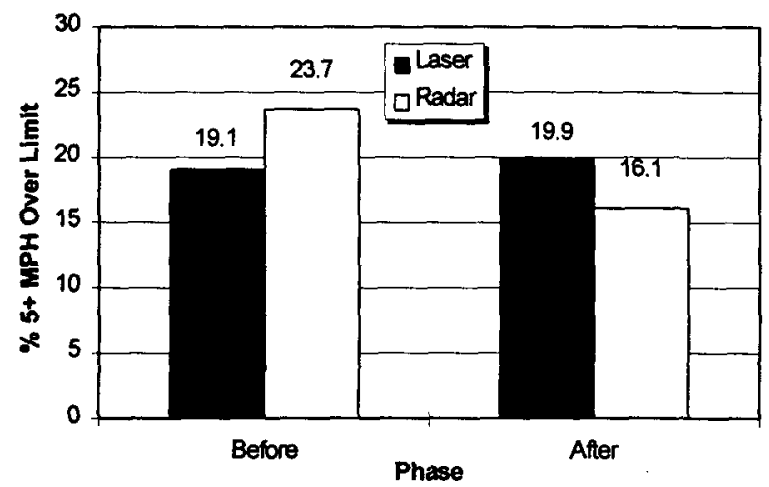

Figure 3-4: Percent Over Limit

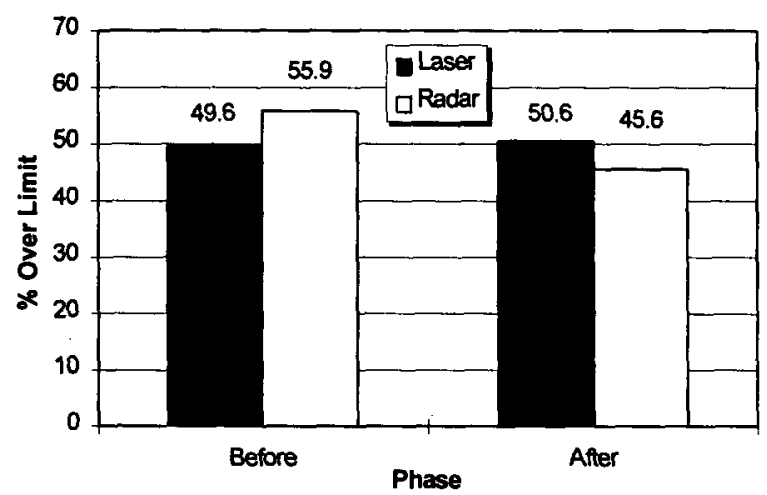

Figure 3-6: Percent 10+ MPH Over Limit

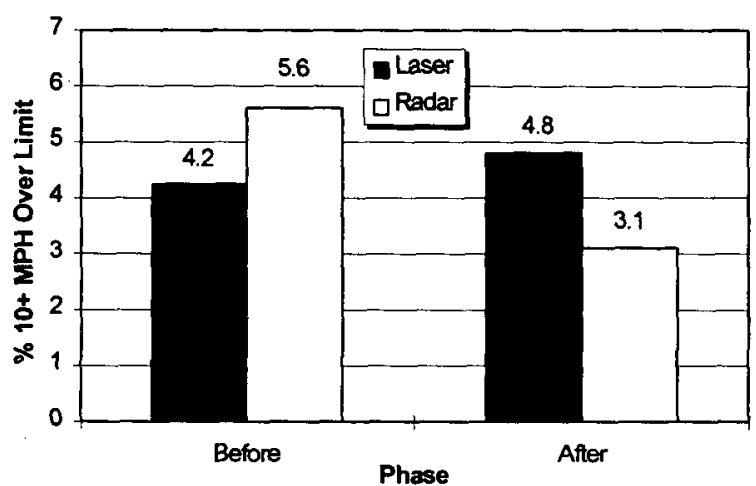


From the graphs it may be seen that the largest percentage reductions were in measures most affected directly by enforcement, percent $5+$ mph over the limit (32\%) and percent $10+$ mph over the limit (45\%).

\section{DISCUSSION}

Our analyses show a reduction in several measures of speeding in the Dubuque radar site, and no change or a small increase in those measures in the Council Bluffs laser site. There is some evidence to suggest that the speed reductions observed in Dubuque were attributable to its speed enforcement program which relied entirely on radar speed measuring devices (RSMDs). The question is: why did Council Bluffs, which used laser speed measuring devices (LSMDs) exclusively, not show positive results? Three factors may have contributed to the absence of an improvement in speed-limit compliance in the laser community: a higher baseline level of speed limit compliance in the laser community, more baseline enforcement in the laser community, and the replacement of all moving enforcement in the laser site with stationary enforcement.

The difference in the level of speeding in the two communities prior to initiation of the study was substantial. Figure 3-7 shows the higher level of speed limit compliance in the radar site as compared to that in the laser site.

Figure 3-7: Unadjusted Means of Three Speed Measures in the Two Study Communities (Data From Entire Study Period)

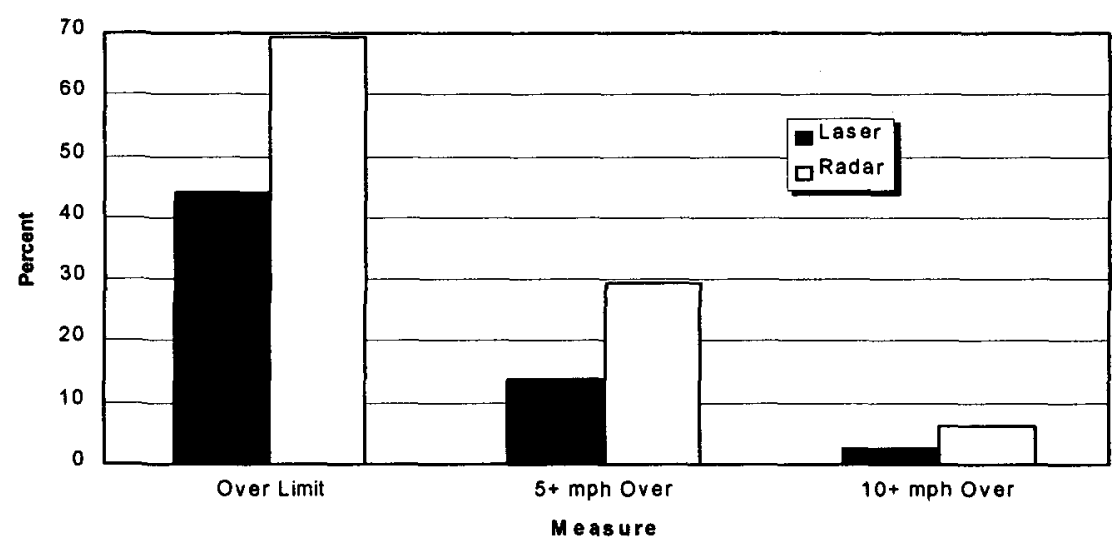


Given that the laser site had achieved a higher level of baseline speed limit compliance, it is likely that achieving still higher levels would be more difficult. This difference could not have been known prior to the start of the program, since speed data were not available at that time.

A second reason for not seeing a change in the laser community was that its total speeding enforcement activity (as measured by monthly speeding citations) was up by $44 \%$ during the test period, while in the radar site it was up by $98 \%$. The laser site might also have achieved a decrease in speeding had it been able to increase its enforcement activity as much as the radar site.

A third reason for the difference is that the laser site was required (as a part of the experimental design) to replace all of its radar enforcement with laser enforcement. This resulted in the elimination of all moving enforcement and may have changed the nature of the enforcement threat. This threat may have actually been lessened for those drivers who avoid speeding because of the chance that any unmarked car could be a police car measuring speeds.

Apart from these reasons, the possibility also exists that the laser speed measuring devices did not create as effective a deterrent threat as did the radar speed measuring devices. Because of their narrow beam, LSMDs do not advertise their presence to non-targeted vehicles. By contrast, RSMDs do advertise their presence to drivers equipped with radar detectors. Further, research suggests that a fairly large percentage of speeding drivers use radar detectors -- for example, Teed and Lund (1993) report that $26 \%$ of drivers ticketed for speeding by officers using LSMDs in Charleston, South Carolina had radar detectors. Thus, to create a public awareness of laser-based enforcement, police in Council Bluffs had to rely more on publicity than did police in Dubuque. Despite an attempt by the Council Bluffs Police Department to create awareness through a publicity program, the program did not succeed in increasing speeders' awareness enough to deter speeding.

It is noteworthy that most of the officers who used the LSMDs in Council Bluffs were quite pleased with them. They found the LSMD speed measurements to be much less likely to be disputed in court and experienced no problems in gaining judicial acceptance of the technology. The officers' main objection was their inability to use lasers for moving enforcement when conditions were favorable (such as interstate highways). 


\section{CONCLUSIONS AND RECOMMENDATIONS}

\section{CONCLUSIONS}

As a result of the Phase 2 implementation and evaluation of two community-wide speed enforcement programs in lowa, the following conclusions may be drawn:

1. The radar-based speed enforcement program in Dubuque, Iowa had a positive communitywide effect on speeding, decreasing the percentage of vehicles traveling 5 and $10 \mathrm{mph}$ or more over the posted speed limit by about $20 \%$ each.

2. The laser-based enforcement program in Council Bluffs, Iowa did not have a communitywide effect in reducing speeding. However, speed limit compliance was maintained at preprogram levels. The absence of any speed reductions in the laser site may have been influenced by the following:

- a higher baseline level of speed limit compliance in the laser community than in the radar community,

- a higher baseline level of speed limit enforcement in the laser community than in the radar community, and

- the replacement (as required by the experimental design) of a prior enforcement strategy using moving vehicles for detecting speed violators.

3. Because they do not create a widely-dispersed, easily-detectable signal, laser-based speed measuring devices may have an inherently lower deterrent effect than do radar-based speed measuring devices. If this is so, publicity is critical to speed enforcement programs that rely on the use of lasers. 
4. Laser speed measuring devices performed well from an operational standpoint, and can be used effectively in prosecuting accused speeders.

5. A systematic program of radar enforcement was shown to be effective in deterring speeding.

\section{RECOMMENDATIONS}

The following recommendations are made regarding the use of laser speed measuring devices:

1. Laser speed measuring devices should be used to augment rather than replace existing radar speed measuring devices.

2. Laser speed measuring devices should be considered for use in situations where vehicle targeting is critical, for example, measuring the speed of a vehicle in a congested stream of traffic.

3. Radar speed measuring devices, with their widespread and easily-detected signal, are wellsuited to situations where drivers equipped with radar detectors need to have their speeds reduced.

4. Further field tests should be conducted to determine the community-wide effectiveness of a laser-based speed enforcement program using a mixed force of laser speed measuring devices and radar speed measuring devices. In such tests, the radar devices would be retained for applications in which they would be more appropriate, for example, speed measurement from a moving vehicle, and for driving populations difficult to reach with publicity activity. 


\section{REFERENCES}

Jones, R.K.; Joscelyn, K.B.; Bennett, R.R.; Fennessy, E.F.; Komoroske, J.H.; Marks, M.E.; and Ruschmann, P.A. 1980. Police enforcement procedures for unsafe driving actions. Volume II: A review of the literature. Final report. Washington, DC: National Highway Traffic Safety Administration.

Jones, R.K.; Joksch, H.C.; Lacey, J.H.; Wiliszowski, C.H.; and Marchetti, L.M. (1995). Field test of combined speed, alcohol, and safety belt enforcement strategies. Washington, DC: National Highway Traffic Safety Administration.

Jones, R.K.; and Lacey, J.H. (In Press). Evaluation of a speeding campaign in Chattanooga, Tennessee. Washington, DC: National Highway Traffic Safety Administration.

Joscelyn, K.B.; Bryan, T.H.; and Goldenbaum, D.M. 1971. A study of the effects of law enforcement on traffic flow behavior. Bloomington, IN: Institute for Research in Public Safety, Indiana University.

Joscelyn, K.B.; Jones, R.K.; and Elston, P.A. 1970. Maximum speed limits. Volumes I, II, III, and $I V$. Washington, DC: National Highway Safety Bureau.

Teed, N.; Lund, A.K.; and Knoblauch, R. (1991). The duration of speed reductions attributable to radar detectors. Accident Analysis and Prevention 22(2):131-137.

Teed, N.; and Lund, A.K. (1993). The effect of laser speed-measuring devices on speed limit law enforcement in Charleston, South Carolina. Accident Analysis and Prevention 25(4): 459-463. 
LASER AND RADAR BASED PROGRAMS FOR DETERRENCE OF SPEEDING 


\section{APPENDIX A - PHASE 1 RESULTS}

\section{TEST OBJECTIVE AND APPROACH}

The objective of the preliminary test was to determine the extent to which a sample of currently available LSMD detectors can provide drivers sufficient warning of an operating LSMD for the drivers to reduce the speed of their vehicle to less than that which would trigger an enforcement action for speeding. The test was to be conducted over a sufficient range of operating conditions to provide a reasonable estimate of the ability of a LSMD to operate effectively in the presence of LSMD detectors.

The preliminary test was conducted in Charleston County, South Carolina in cooperation with the Charleston County Sheriff's Department. This agency had been using the LTI 20.20 LSMD operationally over the year preceding the test and was operating seven such devices at the time of the test. The agency had also tested the Kustom Signals ProLaser, and its officers were trained in the use of that device. Both devices were used in the test.

Two different types of tests were conducted, static tests and dynamic tests. The static tests used non-moving vehicles as targets for the LSMDs. Their objective was to determine the relative performance of several makes of laser detectors under idealized conditions and to provide a basis for selecting a single make of detector for subsequent dynamic tests. The dynamic tests followed an on-the-road test strategy. They attempted to simulate characteristics of several commonly-used enforcement tactics and situations in which speed measuring devices are used. The dynamic tests were conducted at two nominal speeds, a high speed condition (65 mph), and a low speed condition ( $45 \mathrm{mph}$ ). 
Both types of tests were conducted in a highway setting involving flat segments of divided highway with light to moderate traffic density and volume. The LSMDs were operated by a police officer in a vehicle parked by the side of the highway, or in the median strip. An observer / recorder was placed with each test vehicle and with the LSMD operator. Radio communications were maintained among test vehicles and the LSMD operator.

The test vehicles and the LSMD station were operated by sworn officers of the Traffic Division of the Charleston County Sheriff's Department under the supervision of the Division's commander, Lt. Richard Allen.

\section{TEST SERIES}

Four series of tests were conducted. These series and their objectives were:

- Series 1 - Static Test, to determine the relative performance of several makes of laser detectors under idealized conditions and to provide a basis for selecting a single make of detector for subsequent dynamic tests;

- Series 2 - Single Vehicle Dynamic Test, to determine the ability of the selected laser detector in a single vehicle traveling alone on a highway to detect LSMD operation and to avoid enforcement action by slowing to below the effective speed limit;

- Series 3 - Vehicle in Proximity Dynamic Test, to determine the ability of a vehicle traveling in close proximity to other vehicles to detect LSMD operation employing a platoon enforcement strategy and to avoid enforce-

ment action by slowing down to below the effective speed limit. (In a platoon enforcement strategy, an officer using a LSMD successively 
measures the speed of two or more vehicles traveling in the same platoon.); and

- Series 4 - Beam Reflection Dynamic Test, to determine the ability of a vehicle traveling alone toward an area of intensive LSMD enforcement to detect the LSMD enforcement activity and avoid enforcement action by slowing down to below the effective speed limit.

Passenger cars were used in the Series 1,2, and 4 tests; passenger cars and a truck were used in the Series 3 tests. All runs were made during daylight hours.

\section{Series 1 Static Test}

This series of tests involved two test vehicles, both passenger cars (Figure A-1). Vehicle "A" was a 1993 Lincoln Town Car, and vehicle "B" was a 1993 Pontiac Sunbird. Vehicle " $A$ " was equipped with a laser detector, and vehicle "B" was not equipped with a laser detector. The two vehicles were placed close together on a level range in two configurations, side-by-side and fore-and-aft. The tests were conducted at two nominal ranges, 500 feet 1,000 feet. For a given combination of range, LSMD, and laser detector, the LSMD operator took three range readings:

1. from vehicle "A,"

2. from vehicle " $B$ " positioned to the side of vehicle " $A$ " (approximately eight feet center to center of the vehicles), and

3. from vehicle " $B$ " positioned directly in front of vehicle " $A$ " (approximately six feet from rear bumper of vehicle " $B$ " to front bumper of vehicle "A"). 
Figure A-1: Illustration of Static Test Configurations (Series 1)

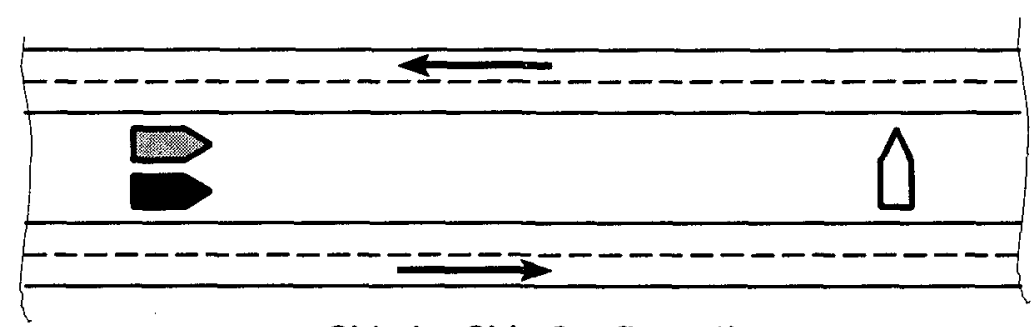

Side-by-Side Configuration

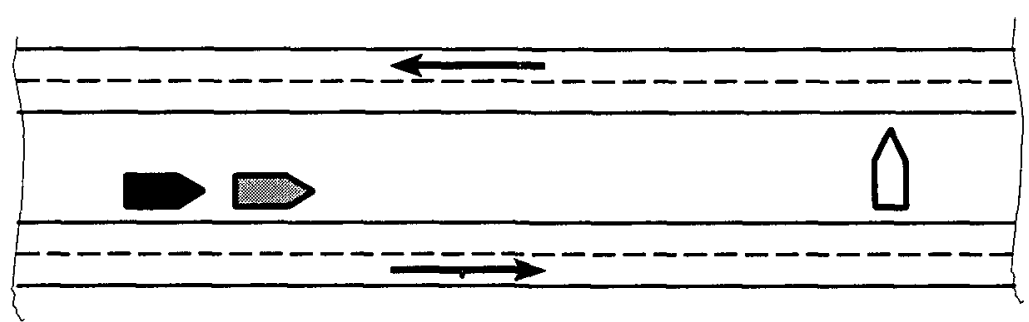

Fore-and-Aft Configuration

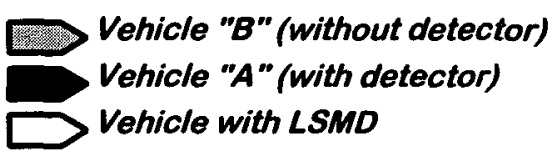

For each trial, the observer in vehicle "A" scored either a "Y" (LSMD operation detected) or an "N" (LSMD operation not detected). The observer at the LSMD station recorded the actual measured range for each trial (five trials for each set of variables).

Five different makes of laser detectors were used in the Series 1 test. The detectors were marked " $A$ " through " $E$," respectively. The laser detectors were positioned horizontally approximately in the center of the vehicle, and vertically just high enough above the dashboard to provide an unobstructed view of the road ahead. Both the vehicle and the detectors were pointed forward. The tests were conducted on November 15, 1993 beginning at approximately 11:00 AM and concluding at approximately 4:30 PM. The weather was clear and calm with temperatures in the $80^{\circ}-85^{\circ} \mathrm{F}$. range. The test range was set up in the median strip of Theresa Drive, 
a four-lane divided city street in North Charleston. Traffic was light to moderate during the tests.

A total of 300 LSMD measurements were taken for this series, with values of the variables as shown in the following table:

\begin{tabular}{cccccc} 
Range & Configurations & Detectors & LSMDs & Targets & Trials \\
\hline \multirow{2}{*}{$500 \mathrm{ft.}$} & Side-by-side & A-E & 1,2 & A,B & 100 \\
& Fore-and-aft & A-E & 1,2 & B & 50 \\
\multirow{3}{*}{$1,000 \mathrm{ft.}$} & Side-by-side & A-E & 1,2 & A,B & 100 \\
& Fore-and-aft & A-E & 1,2 & B & 50 \\
\hline
\end{tabular}

Static testing was also attempted at longer ranges, but testing at longer ranges proved impractical because of difficulties in sighting and resolving the closelyspaced vehicles at ranges greater than 1,000 feet.

Series 2 Single Vehicle Test

This series involved a single test vehicle with a laser detector, isolated from other vehicles using the highway (Figure A-2). The LSMD operator measured the speed of the test vehicle at two different speeds, $45 \mathrm{mph}$ and 65 , and at two different ranges, 500 feet and 1,000 feet. An orange cone was placed at each of these two ranges to indicate where the speed measurement would occur.

For each trial, the observer in the moving vehicle scored either a "Y" (LSMD operation detected) or an "N" (LSMD operation not detected). The observer in the vehicle also recorded the actual speed at the nominal range. The observer at the LSMD station recorded the measured speed and the measured range for each trial. 
Figure A-2: Diagram of Setup for Series 2 Tests

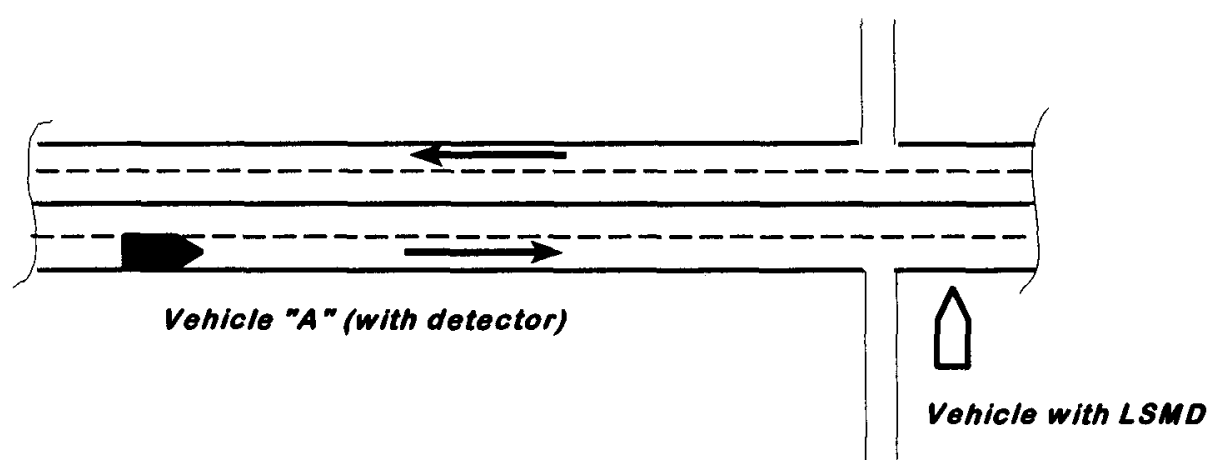

A single make of laser detector (detector " $B$ ") was used in the Series 2 test. The test vehicle was a 1991 Ford Mustang police cruiser. As with Series 1, the laser detector was positioned horizontally approximately in the center of the vehicle, and vertically just high enough above the dashboard to provide an unobstructed view of the road ahead. Both the vehicle and the detectors were pointed forward toward the LSMD station.

The tests were conducted on November 16, 1993 beginning at approximately 8:00 AM and concluding at approximately 10:00 AM. The weather was clear with temperatures in the $80^{\circ}-85^{\circ} \mathrm{F}$. range. The test range was the southbound lanes of Route 177 (Folly Road), a four-lane divided highway in North Charleston. The LSMD station was located on the west side of the highway with the LSMDs pointing northward. The test vehicle approached the LSMD station from the north traveling southbound from a distance of about 2,000 feet. Traffic was light during the tests.

A total of 60 LSMD measurements were taken for this series, with values of the variables as follows: 


\begin{tabular}{cccc} 
Range & Speed & LSMDs & Trials \\
\hline $500 \mathrm{ft}$ & $45 \mathrm{mph}$ & 1,2 & 20 \\
& $65 \mathrm{mph}$ & 1,2 & 20 \\
$1,000 \mathrm{ft}$ & $45 \mathrm{mph}$ & 1,2 & 20 \\
\hline
\end{tabular}

Series 3 Vehicle in Proximity Test

This series employed two test vehicles in close proximity, but isolated from other vehicles using the highway (Figure A-3). One test vehicle was operating a laser detector (target vehicle " $\mathrm{A}$ ") and the other was not operating a laser detector (target vehicle "B"). Two vehicle configurations were tested, vehicles traveling side-by-side and vehicles traveling in a fore-and-aft arrangement. Also, two types of vehicles were tested, a passenger car and a truck. In some runs vehicle " $\mathrm{A}$ " was a car, and in other tests, vehicle " $A$ " was a truck.

In all runs, the LSMD operator first measured the speed of the vehicle not operating the laser detector, and then measured the speed of the vehicle operating the laser detector. The test vehicle with the laser detector attempted to slow down to the effective speed limit immediately after receiving the response signal from the laser detector. The vehicles were tested only at the lower speed (45 mph) for safety considerations, and at two nominal ranges, 500 feet and 1,000 feet.

For each trial, the observer in the vehicle with the detector scored either a "Y" (LSMD operation detected) or an "N" (LSMD operation not detected). This observer also recorded the actual speed at the nominal range. The observer at the LSMD station recorded the measured speed of both vehicles and the measured range of the first vehicle measured for each trial (five trials for each set of variables). 
Figure A-3: Diagram of Setup for Series 3 Tests
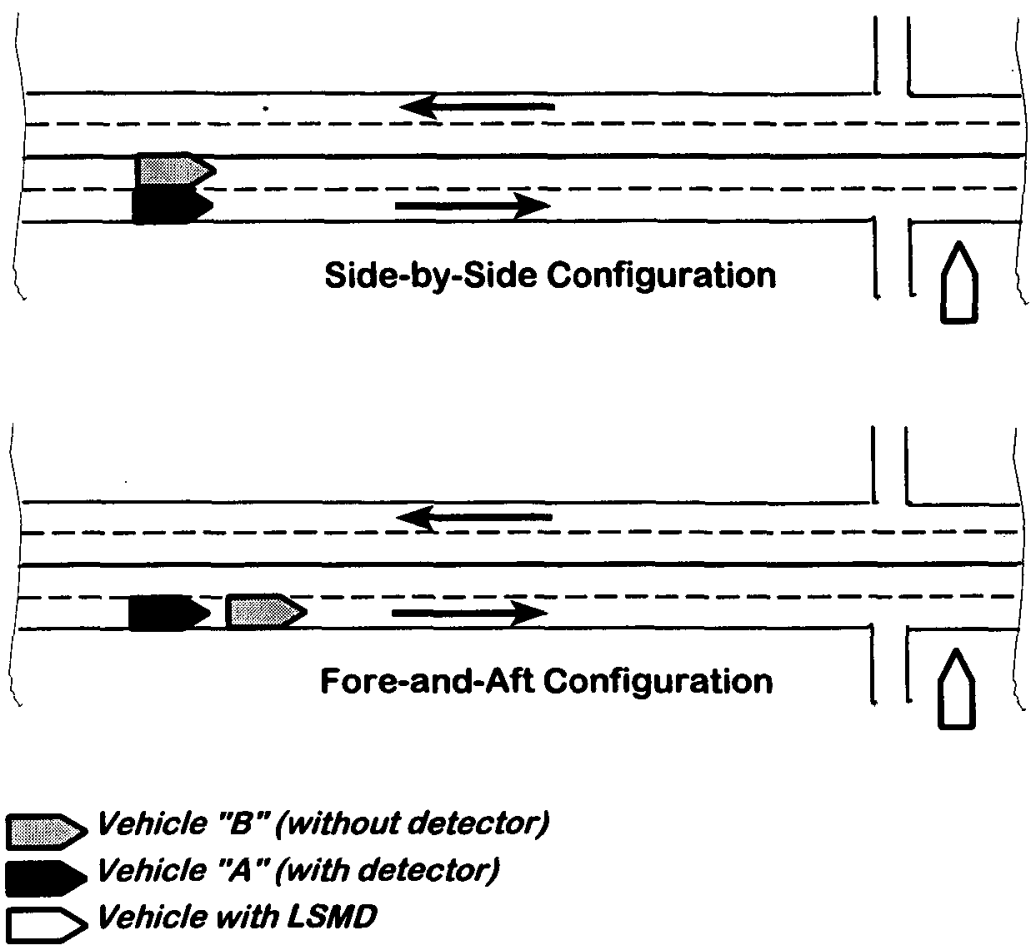

As in Series 2, a single make of laser detector (detector "B") was used in the Series 3 test. Two makes of passenger cars were tested, a 1991 Ford Mustang police cruiser, and a 1993 Ford Crown Victoria police cruiser. The laser detector was positioned horizontally approximately in the center of the vehicle, and vertically just high enough above the dashboard to provide an unobstructed view of the road ahead.

The tests were conducted on November 16, 1993 beginning at approximately 11:00 AM and concluding at approximately 4:00 PM. The weather was clear with temperatures in the $80^{\circ}-85^{\circ} \mathrm{F}$. range. The test range was that indicated for the Series 2 test. Traffic was light during the tests.

A total of 60 LSMD measurements were taken for this series, with values of the various variables as shown in the table below. 
An additional group of 20 tests was conducted to determine whether the LSMD action against vehicle " $\mathrm{A}$ " or the action against vehicle " $\mathrm{B}$ " triggered the detector in the prior Series 3 runs. In these tests, only vehicle " $B$ " (the vehicle without the detector) was the target of the LSMD. Two configurations were tested against both LSMDs, two cars side-by-side and two cars positioned in the fore-and-aft arrangement.

\begin{tabular}{clccc} 
Range & \multicolumn{1}{c}{ Configuration } & $\begin{array}{c}\text { Vehicle Type, } \\
\text { Vehicle "A" }\end{array}$ & LSMDs & Trials \\
\hline $500 \mathrm{ft}$ & $\begin{array}{l}\text { Side-by-side, car- } \\
\text { truck }\end{array}$ & Car & 1,2 & 10 \\
$1,000 \mathrm{ft}$ & $\begin{array}{l}\text { Side-by-side, car- } \\
\text { truck }\end{array}$ & Car & 1,2 & 10 \\
\multirow{5}{5}{$500 \mathrm{ft}$} & $\begin{array}{l}\text { Fore-and-aft, car- } \\
\text { truck' }\end{array}$ & Truck & 1,2 & 10 \\
$1,000 \mathrm{ft}$ & $\begin{array}{l}\text { Fore-and-aft, car- } \\
\text { truck }\end{array}$ & Truck & 1,2 & 10 \\
& $\begin{array}{l}\text { Fore-and-aft, car- } \\
500 \mathrm{ft}\end{array}$ & Car & 1,2 & 10 \\
$1,000 \mathrm{ft}$ & $\begin{array}{l}\text { Fore-and-aft, car- } \\
\text { car }\end{array}$ & Car & 1,2 & 10 \\
\hline
\end{tabular}

'Vehicle " $B$ " the forward vehicle

Series 4 Beam Reflection Test

These tests involved a single test vehicle with a laser detector approaching the LSMD station at $45 \mathrm{mph}$ from about 2,000 feet upstream of traffic being subjected to LSMD speed enforcement (Figure A-4). On each trial, the test vehicle fell in 
some 50 to 100 feet behind the last vehicle in a group of three or more vehicles in the traffic stream. The speeds of the vehicles in the group preceding the test vehicle were then measured by the LSMD when the vehicles entered the speed-enforcement zone (approximately 500 feet from the LSMD). Then, the speed of the test vehicle was measured when it entered the enforcement zone.

Figure A-4: Diagram of Setup for Series 4 Tests

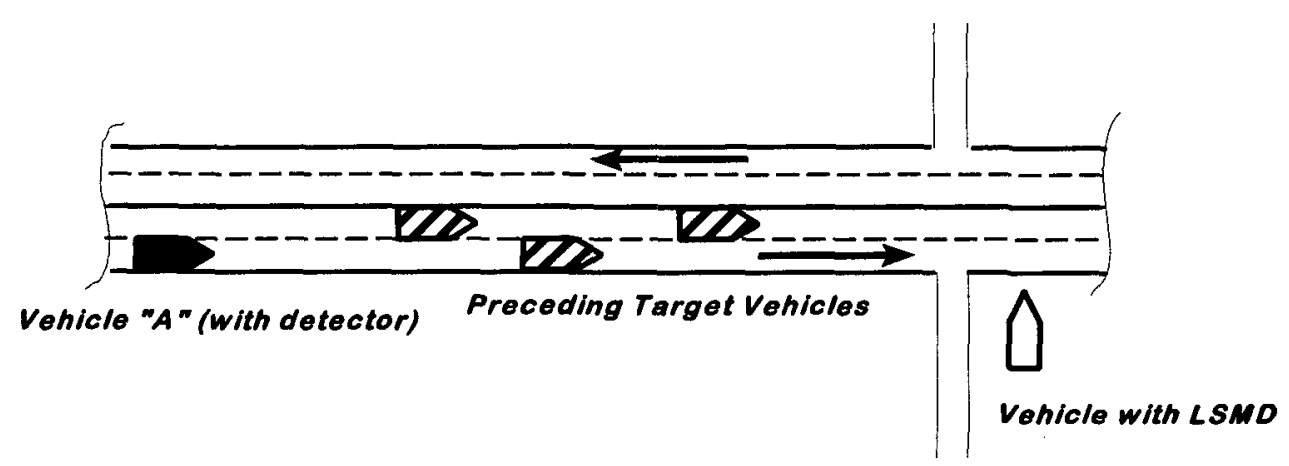

For each trial, the observer in the test vehicle scored either a "Y" (LSMD operation detected) or an "N" (LSMD operation not detected). The observer in the vehicle also recorded the actual speed at the nominal range. The observer at the LSMD station recorded the measured speed and the measured range for each trial.

A single make of laser detectors (detector "B") was used in the Series 2 test. The test vehicle was a 1991 Ford Mustang police cruiser. Again, the laser detector was positioned horizontally approximately in the center of the vehicle, and vertically just high enough above the dashboard to provide an unobstructed view of the road ahead. Both the vehicle and the detectors were pointed forward toward the LSMD station.

The tests were conducted on November 17, 1993 beginning at approximately 10:30 AM and concluding at approximately 11:00 AM. The weather was clear and calm with temperatures in the $80^{\circ}-85^{\circ} \mathrm{F}$. range. Traffic was light to moderate during the tests. 
A total of 10 LSMD measurements were taken for this series, five for each type of LSMD.

\section{Summary of Test Runs}

The table below summarizes the number of conditions for each major series of test. A total of 430 measurements were made, not including the 20 additional measurements made in Series 3.

\begin{tabular}{|c|c|c|c|c|c|c|c|}
\hline Series & $\begin{array}{l}\text { LSMD } \\
\text { Makes }\end{array}$ & $\begin{array}{c}\text { Detector } \\
\text { Makes }\end{array}$ & $\begin{array}{l}\text { Config- } \\
\text { urations }\end{array}$ & Ranges & Speeds & Iterations & $\begin{array}{c}\text { Total } \\
\text { Measure- } \\
\text { ments } \\
\end{array}$ \\
\hline 1 & 2 & 5 & 3 & 2 & 1 & 5 & 300 \\
\hline 2 & 2 & 1 & 1 & 2 & 2 & 5 & 60 \\
\hline 3 & 2 & 1 & 3 & 2 & 1 & 5 & 60 \\
\hline 4 & 2 & 1 & 1 & 1 & 1 & 5 & 10 \\
\hline All & - & -- & -- & -- & -- & -- & 430 \\
\hline
\end{tabular}

\section{RESULTS}

Static Tests

As indicated in the prior chapter, the static tests were conducted in Series 1. A total of 300 measurements were taken for 60 different combinations of values of the test variables. (For each combination of values, there were five measurements.)

Overall, the laser detector gave a response in $43 \%$ of the trials. However, when the vehicle without the detector (vehicle "B") was the target, only $18 \%$ of the trials resulted in a response. When the vehicle with the detector (vehicle " $A$ ") was the target, the detector responded in $92 \%$ of the trials. However, all of these latter 100 
trials were for the vehicles placed side-by-side in a side-by-side configuration. When vehicle " $\mathrm{B}$ " was the target in this configuration (100 trials), no responses were given. But when vehicle " $B$ " was the target in the fore-and-aft configuration (100 trials), a response was given in $36 \%$ of the trials.

The detectors were more likely to give a response at the higher range (1,000 feet) than at the lower range (500 feet). Fifty-one percent of the trials at 1,000 feet resulted in a response compared to $35 \%$ of the trials at 500 feet. This difference was significant at the 0.007 level (Fisher's Exact Test).

The detectors were also more likely to give a response when LSMD number 2 (the ProLaser) was used than when LSMD number 1 (the LTI 20.20) was used. The ProLaser resulted in a response in $54 \%$ of the trials in which it was used, and the LTI 20.20 resulted in a response in $31 \%$ of its trials. This difference was also highly significant $(p=0.0001)$. This difference was almost entirely an effect of vehicle configuration. When the vehicles were placed side-by-side, the percentage of trials resulting in a response did not differ significantly for the two LSMDs ( $48 \%$ for the ProLaser versus $44 \%$ for the LTI 20.20). However, when the vehicles were placed in a fore-and-aft configuration, $66 \%$ of the ProLaser trials resulted in a response versus only $6 \%$ of the LTI 20.20 trials.

Finally, the Series 1 trials $(n=60$ for each make of detector) indicated no significant difference in percentTable A-1: Detector Make Code vs. Response age of responses with respect to make of laser detector. Percentage of responses varied from $40 \%$ for detectors $\mathrm{D}$ and $\mathrm{E}$ to $47 \%$ for detector $\mathrm{C}$, compared to an overall C Response Detector No Yes
$56.67 \quad 43.33$

A mean of $43 \%$ (Figure A-4). There were slight differences in percentage of responses with respect to some D $\quad 60.00 \quad 40.00$ of the other variables, but none of these differences was E $\quad 60.00 \quad 40.00$ significant. For example, in the side-by-side configuration, detectors $\mathrm{B}$ and $\mathrm{C}$ each responded $50 \%$ of the 
time compared to $45 \%$ for detectors $\mathrm{A}$ and $\mathrm{D}$, and $40 \%$ for detector $\mathrm{E}$. In the foreand-aft configuration, detectors $\mathrm{A}, \mathrm{C}$, and $\mathrm{E}$ all responded $40 \%$ of the time, compared to $30 \%$ for $B$ and $D$. When the target vehicle was the vehicle with the detector, detectors $\mathrm{B}$ and $\mathrm{C}$ responded $100 \%$ of the time compared to $90 \%$ for $\mathrm{A}$ and $\mathrm{D}$, and $80 \%$ for $\mathrm{E}$.

We also modeled the variable "response" (a $0 / 1$ variable) as a function of the variables "detector," "range," "LSMD," "configuration", and "target vehicle." This has the effect of controlling for range, LSMD, configuration, and target vehicle. Interaction effects between response and each of the other independent variables were included in some runs. The SAS GLM procedure was used in the model. The model also indicated no significant effects of detector, nor of any of its interactions, with respect to response.

The decision regarding which detector to select for the dynamic tests had to be made in the field without the benefit of analyses of the type indicated above. The main criterion for selection was the highest number of responses given. Inspection of the data suggested that detectors $\mathrm{A}, \mathrm{B}$, and $\mathrm{C}$ had slightly best performance with respect to responses. Examination of detectors $\mathrm{A}$ and $\mathrm{B}$ revealed that they were the same with slightly different packaging. Detector $\mathrm{C}$ was determined to be unsatisfactory for the remaining series because of the long warning signal it emitted, making it difficult to separate closely spaced LSMD bursts. Detector B was selected over detector $\mathrm{A}$ on the basis of slightly better packaging and ease of use.

\section{Dynamic Tests}

Overall Results. The dynamic tests were conducted in Series 2, 3, and 4. Overall, the laser detector responded in $89 \%$ of the 130 trials in all three series. However, the drivers were able to reduce their speed by more than $5 \mathrm{mph}$ in only $9 \%$ of the trials, and were able to reduce their speed by more than $10 \mathrm{mph}$ in just $4 \%$ of the trials. All of the five speed reductions of more than $10 \mathrm{mph}$ were against the 
ProLaser, and five out of the seven speed reductions in the 6-10 mph range were against the ProLaser. The mean speed reduction over all trials was $1.7 \mathrm{mph}$.

With respect to the nominal speed of the test vehicle, $24 \%$ of the higher-speed trials $(65 \mathrm{mph}$ ) had speed reductions of more than $5 \mathrm{mph}$. By contrast, only $6 \%$ of the lower-speed trials $(45 \mathrm{mph}$ ) had speed reductions of more than $5 \mathrm{mph}$. A similar relationship held for speed reductions of more than $10 \mathrm{mph}-12 \%$ for the higher nominal speed versus $2 \%$ for the lower nominal speed. These differences are significant at the 0.016 level. There was no significant difference in speed reduction with respect to nominal speed, but there was a significant difference in responses with respect to nominal range $(p=0.042)$. At the lower range, $84 \%$ of the trials resulted in a response versus $96 \%$ at the higher range.

The planned nominal ranges and speeds were maintained within reasonable tolerances during the dynamic tests. For the nominal ranges of 500 feet and 1,000 feet, the means of the ranges measured by the LSMDs were 470 feet and 1,062 feet, respectively. For the nominal speeds of $45 \mathrm{mph}$ and $65 \mathrm{mph}$, the means of the speeds being traveled when the detector response was received were $44.5 \mathrm{mph}$ and 65.0 mph, respectively.

Series 2 Results. The laser detector responded in $90 \%$ of the 60 trials in this series. Responses were slightly more frequent when the ProLaser was used, and also at the longer nominal range. However, only the difference with respect to range (100\% responses at 500 feet versus $84 \%$ at 1,000 feet) approached statistical significance for this sample size $(\mathrm{p}=0.07)$.

Despite the high percentage of responses given by the laser detectors, speed reductions of more than $5 \mathrm{mph}$ occurred in only $12 \%$ of the 60 trials in this series. Seventeen percent of the ProLaser trials resulted in speed reductions of more than 5 mph compared to $4 \%$ for the LTI 20.20 . Speed reductions of more than $10 \mathrm{mph}$ occurred in $5 \%$ of the 60 trials in this series. Nine percent of the ProLaser trials resulted in speed reductions of more than $10 \mathrm{mph}$ compared to none for the LTI 20.20. Again, these differences were not statistically significant for this sample size 
$(\mathrm{p}=0.33)$. Speed reductions were more frequent at the longer nominal range $(\mathrm{p}=0.13)$ and the lower nominal speed $(\mathrm{p}=0.032)$.

Series 3 Results. The laser detector responded in $88 \%$ of the 60 trials in this series, but the driver was able to reduce speed by more than $5 \mathrm{mph}$ in only $7 \%$ of the trials, and by more than $10 \mathrm{mph}$ in just $2 \%$ of the trials (one trial out of the 60 ). Responses were more frequent $(\mathrm{p}=0.19)$ for the two fore-and-aft configurations (carcar and car-truck, 95\% for each configuration) than for the side-by-side configuration (75\%). All of the speed reductions were for vehicles in a fore-and-aft configuration. There were no clear differences for any of the other variables (i.e., nominal range, nominal speed, or LSMD) with respect to responses or speed reductions.

The 20 separate trials in which only the accompanying vehicle was target of the LSMD revealed no responses nor any speed reduction of more $5 \mathrm{mph}$.

Series 4 Results. This was a short series with only 10 trials. The laser detector responded in nine of these trials, but the driver was able to reduce speed measurably in only one trial (from $45 \mathrm{mph}$ to $34 \mathrm{mph}$ ). This one speed reduction occurred against the ProLaser.

\section{Summary}

The static tests (Series 1) established that the detectors tested responded when an LSMD was aimed directly at the vehicle with a detector, but did not respond when an LSMD was aimed at a vehicle to the side of it. When the LSMD was aimed at the vehicle with a detector, the detector responded in $92 \%$ of the trials. However, when the vehicle along side the vehicle with the detector was the target, none of the trials resulted in a warning to the vehicle with the detector. The detectors fared better when the LSMD target was the lead vehicle in the fore-and-aft configuration. For this condition, the trailing vehicle's detector responded in $36 \%$ of the trials. The Series 1 runs also showed that there was no significant difference in detection 
performance among the five detectors tested. The single detector used in subsequent series was chosen on the basis of slightly better packaging and ease of use.

The results of the dynamic tests (Series 2, 3, and 4) closely paralleled those of the static tests with respect to the laser detector's ability to give a warning of LSMD usage. The laser detector usually responded, but seldom in time for the drivers to reduce speed to the effective speed limit. In $9 \%$ of the trials, the drivers were able to reduce speed by more than $5 \mathrm{mph}$. In $4 \%$ of the trials, they reduced speed by more than $10 \mathrm{mph}$. All of the five speed reductions of more than $10 \mathrm{mph}$, and five out of the seven speed reductions in the 6-10 mph range, were against one of the LSMDs. We suspect that the larger number of speed reductions was due to the larger amount of time required for this particular device to acquire a target. The mean speed reduction over all dynamic trials was $1.7 \mathrm{mph}$.

The results of the Series 3 and Series 4 tests further underscored the static-test findings regarding the difficulty laser detectors had in responding when an LSMD was being used against other vehicles. In the Series 3 test, the LSMD was first used against a nearby vehicle without a detector and then used against a vehicle with a detector. Yet, in only one trial out of 60 was the driver in the vehicle with the detector able to reduce speed by more than $10 \mathrm{mph}$. In a later short series of 20 trials in which only the vehicle without the detector was targeted by the LSMD, the detector in the accompanying vehicle did not respond in any of the trials. Thus, it is most likely that the one trial in which evasive action was successful in Series 3 was when the LSMD was aimed at the vehicle with the detector. In Series 4 test, LSMDs were first targeted against several vehicles preceding the vehicle with the detector. Yet, in none of these 10 trials was the driver able to reduce speed by even $5 \mathrm{mph}$.

\section{CONCLUSIONS}

The preliminary tests provide strong evidence that current laser detectors are not an effective countermeasure against current LSMDs. The detectors we tested were 
able to respond to an LSMD targeted directly at the detector-equipped vehicle, but by then it was nearly always too late for the speeding driver to slow down to the effective speed limit. Further, the laser detectors were almost never able to respond to LSMD use against other vehicles near to a vehicle with a detector. 
LASER AND RADAR BASED PROGRAMS FOR DETERRENCE OF SPEEDING 


\section{APPENDIX B - SURVEY FORM}

The lowa Department of Safety needs your help in providing information about highway safety issues. Your answers will be used for statistical purposes only. Please do not write your name on this form.

1. Why are you at the driver's license office? (CIRCLE ONE)
a. To get first license
c. To have license reinstated
e. other
b. To renew currently valid license
d. To get an I.D. only

2. Your sex? (CIRCLE ONE)
a. Male
b. Female

3. Your age? (CIRCLE ONE)
a. under 18
c. $21-24$
e. $30-49$
g. Over 65
b. $18-20$
d. $25-29$
f. 50-65

4. What messages about enforcement of laws on speeding have you heard, seen, or read in the last three months (on TV, radio, in the newspaper, posters, etc.)? Please, write in.

The message

Where seen, heard, or read

5. Have you noticed any increase in enforcement of speeding laws in the past three months? (CIRCLE ONE)
a. Yes
b. No

6. A. Compared with three months ago, are you speeding: (CIRCLE ONE)
a. More often?
b. Less often?
c. About the same?
d. Do not speed

B. If your speeding changed, please say why:

7. Compared with three months ago, would you say that the chances of a speeder getting caught by the police have: (CIRCLE ONE)
a. Increased?
b. Decreased?
c. Stayed about the same? 
LASER AND RADAR BASED PROGRAMS FOR DETERRENCE OF SPEEDING 